\title{
Historical and future climates over the upper and middle reaches of the Yellow River Basin simulated by a regional climate model in CORDEX
}

\author{
Xuejia Wang ${ }^{1,2} \cdot$ Deliang Chen $^{2} \mathbb{D} \cdot$ Guojin Pang $^{2,3} \cdot$ Xiaohua Gou $^{4} \cdot$ Meixue Yang ${ }^{1}$
}

Received: 28 March 2020 / Accepted: 28 December 2020 / Published online: 6 February 2021

(c) The Author(s) 2021

\begin{abstract}
Despite the importance of the Yellow River to China, climate change for the middle reaches of the Yellow River Basin (YRB) has been investigated far less than for other regions. This work focuses on future changes in mean and extreme climate of the YRB for the near-term (2021-2040), mid-term (2041-2060), and far-term (2081-2100) future, and assesses these with respect to the reference period (1986-2005) using the latest REgional MOdel (REMO) simulations, driven by three global climate models (GCMs) and assuming historical and future [Representative Concentration Pathway (RCP) 2.6 and 8.5] forcing scenarios, over the CORDEX East Asia domain at $0.22^{\circ}$ horizontal resolution. The results show that REMO reproduces the historical mean climate state and selected extreme climate indices reasonably well, although some cold and wet biases exist. Increases in mean temperature are strongest for the far-term in winter, with an average increase of $5.6{ }^{\circ} \mathrm{C}$ under RCP 8.5. As expected, the future temperatures of the warmest day (TXx) and coldest night (TNn) increase and the number of frost days (FD) declines considerably. Changes to mean temperature and FD depend on elevation, which could be explained by the snow-albedo feedback. A substantial increase in precipitation (34\%) occurs in winter under RCP 8.5 for the far-term. Interannual variability in precipitation is projected to increase, indicating a future climate with more extreme events compared to that of today. Future daily precipitation intensity and maximum 5-day precipitation would increase and the number of consecutive dry days would decline under RCP 8.5. The results highlight that pronounced warming at high altitudes and more intense rainfall could cause increased future flood risk in the YRB, if a high GHG emission pathway is realized.
\end{abstract}

Keywords Climate projection $\cdot$ Yellow river basin $\cdot$ REMO $\cdot$ Extreme temperature $\cdot$ Extreme precipitation $\cdot$ RCP scenario

Supplementary Information The online version contains supplementary material available at https://doi.org/10.1007/s0038 2-020-05617-4.

Xuejia Wang

xjwang@1zb.ac.cn

$\triangle$ Deliang Chen

deliang@gvc.gu.se

1 State Key Laboratory of Cryospheric Science, Northwest Institute of Eco-Environment and Resources, Chinese Academy of Sciences, Lanzhou, Gansu, China

2 Reginal Climate Group, Department of Earth Sciences, University of Gothenburg, Gothenburg, Sweden

3 Faculty of Geomatics, Lanzhou Jiaotong University, Lanzhou, Gansu, China

4 Key Laboratory of Western China's Environmental Systems (Ministry of Education), College of Earth and Environmental Sciences, Lanzhou University, Lanzhou, Gansu, China

\section{Introduction}

Climate change is one of the most significant challenges encountered by the world in recent centuries and addressing it is urgent (Cubasch et al. 2013). Climate warming is unequivocal and many unprecedented changes have been observed since the 1950s (IPCC 2014, 2019a, b). The increasing emission of greenhouse gases (GHGs) continues to induce warming (Wang et al. 2018a). Under global warming, temperatures increase more rapidly in high altitude regions (Pepin et al. 2015) and spatially variable changes to precipitation are projected. In general, the contrast between the mean precipitation for wet and dry regions, and for wet and dry seasons, will increase as temperature rises (Chou et al. 2013; Liu and Allan 2013; Ghosh 2018). By the end of this century, arid and semi-arid areas are likely to become drier and humid areas will likely experience more rainfall (Collins et al. 2013). However, this "dry gets drier, wet gets 
wetter" paradigm may not hold over all land areas (Hu et al. 2019). Only $10.8 \%$ of global land area fits this paradigm at annual timescales and $9.5 \%$ of global land area is projected to experience the opposite paradigm (Greve et al. 2014). This suggests the paradigm is an oversimplification of precipitation changes that should be anticipated over land.

A growing body of evidence suggests that there are increasing trends in the frequency, intensity, and duration of climate extreme events, such as droughts and floods under climate warming (e.g., Gou et al. 2010; Sun et al. 2014; Seneviratne et al. 2016). China has suffered frequent and severe floods and droughts in recent decades, such as the 1998 flood on the Yangtze River basin (Zong and Chen 2000) and the 2013 drought in eastern China (Sun et al. 2014), and these have caused substantial economic losses and ecosystem destruction (Ahmed et al. 2020; Su et al. 2018). Improving our understanding of climate change and our projections for future change in these sensitive and ecologically fragile regions is crucial for many reasons.

Climate projections are vitally important for evaluation of the future regional impacts of global warming (Arnell et al. 2019). Global climate models (GCMs) are often used to assess regional climate change, however, their coarse resolution means that many smaller-scale processes are not wellresolved, for example atmospheric processes in mountainous topography. The large spread in simulations of present-day climate demonstrates uncertainties that should be associated with simulated projections (Woldemeskel et al. 2016), particularly in the case of precipitation, which is highly variable. Recently, considerable progress has been achieved in high resolution climate modeling, for example in dynamical downscaling over multiple CORDEX (Coordinated Regional Climate Downscaling Experiment) domains (e.g., Jacob et al. 2012; Wang et al. 2016; Gao and Chen 2017; Ge et al. 2019; Giorgi 2019; Niu et al. 2019; Tapiador et al. 2020). These high-resolution simulations have the advantages of improved representation of orographic features, increased spatial resolution, optimized atmospheric forcing, and a detailed land-surface scheme. Regional climate models (RCMs) provide added value to output from GCMs, leading to a better understanding of regional and local climate change signals (Giorgi 2019). They provide more reliable simulations of climate and are therefore indispensable tools for interpretation of the impacts of future climate change.

The Yellow River (YR, Fig. 1b) is the second longest river in China and is known as the "Mother River of China" (Zhang et al. 2018). Originating on the Tibetan Plateau, the Yellow River Basin (YRB) extends eastwards through arid, semi-arid, and semi-humid regions of northern China, including the Loess Plateau, Inner Mongolia, and the Gobi Desert, and then through the plains of east China and eventually into the Pacific Ocean. The YR supports more than 114 million people with drinking water and irrigation,

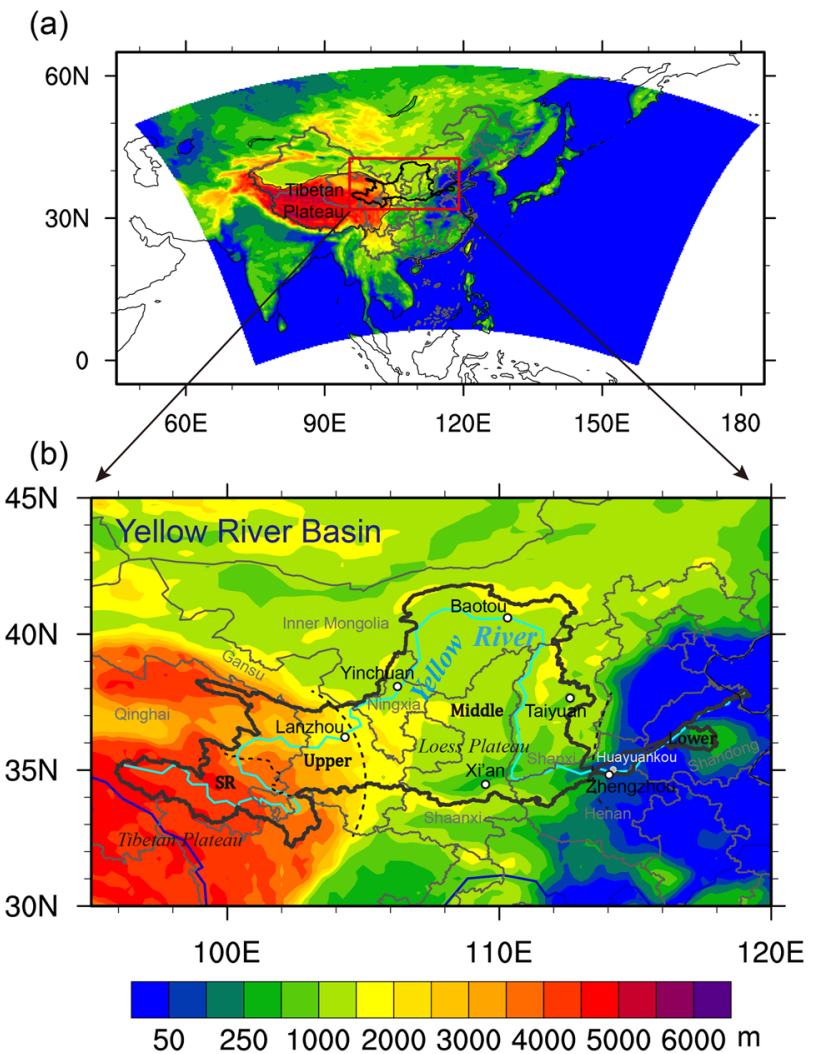

Fig. 1 a REMO simulation domain and $\mathbf{b}$ the location and topography of the Yellow River Basin (YRB) in the REMO simulation. The black dash lines mark the rough boundaries of three topographic regions: upper (altitudes greater than $2000 \mathrm{~m}$ ), middle (between 1000 and $2000 \mathrm{~m}$ ), and lower (less than $1000 \mathrm{~m}$ ) reaches. SR denotes the source region of the YR

which accounts for around $9 \%$ of the total population of China, and supplies water for $12.6 \times 10^{10} \mathrm{~km}^{2}$ of farmland, which accounts for approximately $16.2 \%$ of China's grain yield (Kong et al. 2016). The YRB has frequently suffered from drought and a deficit in water resources (Zhang et al. 2009), which has impacted on ecological conservation and economic development (Zhang et al. 2018). Changes in the supply of water resources are directly linked to climate change and extreme climate events (Zhang et al. 2009; Zhao et al. 2019).

Annual precipitation over the YRB has been decreasing since the 1960s at a rate of $0.31 \mathrm{~mm}$ year $^{-1}$ (Zhao et al. 2019; Zhang et al. 2014). Reported reductions in streamflow in the YR have been attributed to climate change and to human activities such as the intensive water extraction for agricultural irrigation that began in 1986 (Zhang et al. 2009). At the Huayuankou station (Fig. 1b), around $50 \%$ of the decrease in streamflow follows from changes in climate temporal pattern, and the remainder is the effect of changes in climate (25\%), vegetation (5\%), and irrigation (20\%) (Tang et al. 2008). Under the influence of rapid warming, pan evaporation has increased 
significantly since 1986 (Cong et al. 2010) and terrestrial water storage in the YRB has therefore dramatically declined over recent years (Jing et al. 2019). Water scarcity, driven by growing demand and persistent droughts, has more serious implications for water and food security than was recognized until recently (Wang et al. 2019). If precipitation continues to decrease and evaporation keeps unchanged or increases, then the YRB is very likely to face severe water shortages. Different changes in precipitation, for example changes to the mean and/or to the frequency or duration of extreme precipitation events may have implications for flood risk (Donat et al. 2016). Previous studies have used RCMs to project future climate change in the source region of the YR (Hui et al. 2014; Lu et al. 2018). However, despite the importance of the YR to water resources, very few studies consider the whole YRB, including the upper, middle and lower reaches, where using the simplified paradigm to project the future climate could be misleading. In particular, there is a lack of information for likely future climate extremes in response to enhanced GHG emissions.

The climate of the YRB results from many interacting factors and the ecosystem is extremely vulnerable to climate change (Zhang et al. 2018). Despite the sensitivity, little is known about how the climate is likely to evolve over this sensitive region under future climate change, which is the motivation for this study. The YRB is divided into three topographical regions, containing the upper, middle, and lower reaches of the YR. The region downstream of Huayuankou is a narrow basin and changes to streamflow here have been largely attributed to human activity (Tang et al. 2008). This study focuses on the upper and middle reaches. The objectives of the study are: (1) to evaluate the skill of the RCM in reproducing mean climate and climate extremes for the YRB during a historical period driven by GCMs; and (2) to estimate the changes likely for different time periods in the future under Representative Concentration Pathway (RCP) scenarios 2.6 (van Vuuren et al. 2011) and 8.5 (Riahi et al. 2011).

The paper is structured as follows: Sect. 2 describes the method, data, and extreme indices used in this work. Section 3 presents the results of model evaluation, and the changes projected for climate mean and extremes, and the dependency of these on elevation, and identify mechanisms that may drive the changes. The discussion and conclusions are given in Sects. 4 and 5.

\section{Method and data}

\subsection{Regional climate model REMO and experiment design}

The regional climate model, REgional MOdel (REMO), is a three-dimensional regional hydrostatic atmospheric model that uses physical parameterizations from European Centre Hamburg Version 4 (ECHAM-4) (Roeckner et al. 1996) and a dynamical framework from the weather forecast model of the German Weather Service Europa-Modell (Majewski 1991). Following the CORDEX experiment design, REMO has been successfully used for long-term climate simulations over multiple domains, such as Europe, Africa, Asia, America, and the Mediterranean (Jacob et al. 2012; Remedio et al. 2019). The REMO model (version 2015) simulates most climate types relatively well, with a low bias and a high skill score (Remedio et al. 2019; Xu et al. 2018) have shown that REMO (REMO2015), driven by ERA-Interim reanalysis data, can reliably simulate climate over the Tibetan Plateau. We selected REMO simulations available from the CORDEX experiment for the East Asia domain (Fig. 1a). A comprehensive evaluation of REMO simulations driven by the ERA-Interim data found that REMO reliably reproduces the spatial variability of air temperature and precipitation over the YRB, albeit with some biases, such as a cold bias in the upper reaches and a wet bias, and weaker warming trends in four seasons $\left(0.1-0.3{ }^{\circ} \mathrm{C}\right.$ decade $\left.^{-1}\right)$ than have been observed $\left(0.4-0.6^{\circ} \mathrm{C}\right.$ decade $\left.^{-1}\right)$ (Pang et al. 2020). The latest hydrostatic version of REMO (REMO2015), developed at the Climate Service Center Germany (GERICS), has horizontal resolution of $0.22^{\circ}(\sim 25 \mathrm{~km})$ and uses a hybrid sigma-pressure coordinate system with 27 levels. The lower levels follow the surface terrain and the uppermost level is at $10 \mathrm{hPa}$ (Remedio et al. 2019). REMO is coupled with the physically based FLake lake model (REMO-FLAKE) so that lakes are considered interactively and feedbacks are included (Pietikäinen et al. 2018). To avoid inconsistent grid cell dimensions close to the poles, REMO uses a rotated grid. Horizontal grid cells are rotated on an Arakawa-C spherical grid and the Tiedtke comprehensive mass flux convective scheme is used to represent cumulus processes (Tiedtke 1989). Topography is taken from the Global 30 Arc-Second Elevation Data Set (GTOPO30) (https://doi. org/10.5066/F7DF6PQS) and a global land surface dataset, including leaf area index, fractional vegetation cover, and surface albedo, provides the vegetation data required by the model (Hagemann et al. 1999; Hagemann 2002). In the standard configuration of REMO, glacier and ice sheets are represented by a static glacier mask (Kumar et al. 2015).

The atmospheric boundary conditions used for REMO come from three widely used GCMs available from the Coupled Model Intercomparison Project 5 (CMIP5) experiment: HadGEM2-ES (Collins et al. 2011), MPI-ESM-LR (Jungclaus et al. 2013), and NCC-NorESM1-M (Bentsen et al. 2013). The REMO model topography of the study area is shown in Fig. 1b. Results from the REMO simulations driven, separately, by the three GCMs are hereafter referred to as Had_R, MPI_R, and NCC_R. Simulations driven by each GCM assume the low and high emission scenarios 
(RCP2.6 and RCP8.5, respectively) from 1 to 1970 to 31 December 2100, except Had_R which ends on 31 December 2099. The 30-year period 1976-2005 is used as the historical period for model evaluation. Projected changes in mean and extreme temperature and precipitation for the periods 2021-2040 (near-term period, NTP), 2041-2060 (mid-term period, MTP), and 2081-2100 (far-term period, FTP) are assessed relative to the 1986-2005 reference period (RF) over the YRB from the REMO simulations. To evaluate the performance of the REMO model, the three driving GCMs (hereafter Had, MPI, and NCC) for the historical period are also used.

\subsection{Observational dataset}

The gridded daily air temperature and precipitation observation dataset $\mathrm{CN} 05.1$ with a spatial resolution of $0.25^{\circ} \times$ $0.25^{\circ}$ was used for model validation in this study ( $\mathrm{Wu}$ and Gao 2013). The dataset covers all of mainland of China and spans the period 1961-2017. The CN05.1 dataset was generated through interpolation of observations recorded at over 2400 meteorological stations in China using thin-plate smoothing splines constrained by background climatology fields followed by topographical correction. The dataset is temporally and spatially continuous and has been widely used in model validation studies for GCMs and RCMs (Gao et al. 2016; Shi et al. 2018; Wang et al. 2018b, 2020). In addition, we use geopotential height at $500 \mathrm{hPa}$ derived from the ERA-Interim at a spatial resolution of $0.75^{\circ}$ for the RF (1986-2005) (Dee et al. 2011).

\subsection{Method}

The RCM and GCM simulations were bilinearly interpolated into the CN05.1 grid for comparison with the observation data. Topographical corrections for air temperature in the historical period used an assumed lapse rare of $0.65{ }^{\circ} \mathrm{C}$ $100 \mathrm{~m}^{-1}$. To better reflect uncertainty, we calculated the ensemble mean (ENS) (Zhou and Yu 2006) and spread (defined by minimum and maximum change) of the three REMO simulations to describe the simulated climate patterns and changes. Clearly, this three-member ensemble does not show the full spread of potential outcome and should therefore be considered as a first attempt to sample represent the uncertainty range. We used a Taylor diagram (Taylor 2001) to assess differences between the RCM and GCM simulated and observed data to evaluate the REMO model performance. A Taylor diagram shows the ratio of the standard deviations for the model and observation data, and the correlation coefficient (CC) and the root-mean-square difference (RMSD) between the model and observation data.

Changes in extreme values for some climate fields are of greater importance than changes in the mean. In this work, we therefore used six indices for climate extremes, defined according to the expert team on climate change detection and indices (ETCCDI) (Kiktev et al. 2003; Shi et al. 2018), to validate model performance in capturing observed extremes, and to assess the future changes projected for extreme events. The indices comprise three temperature-related indices: the warmest day (TXx), the coldest night (TNn), and the number of frost days (FD); and three precipitationrelated indices: the daily precipitation intensity (SDII), the maximum number of consecutive dry days (CDD), and the maximum 5-day precipitation (RX5day). Note that FD is not indicative of extreme event in the YRB according to the regionally averaged value (Table 1), although it is kept as a special condition in the study because of its importance for agriculture activities, ecosystems, and human societies. Detailed information on the extreme indices is presented in Table 2.

\section{Results}

\subsection{Evaluation of the regional climate model REMO}

\subsubsection{Air temperature}

We assess how well the RCM reproduces the observed climate by analyzing biases in the three REMO simulations driven by the different GCMs for the historical period 1976-2005, relative to observations for the four seasons (Fig. 2). Biases for the three GCM simulations are also shown. There are differences between the biases for each of the three GCMs, relative to the observations. There is a cold bias in December-February (DJF) and a large warm bias in June-August (JJA) in the YRB in the Had simulations, while in the NCC simulations there is a cold bias in DJF and September-November (SON), and the MPI simulation includes a warm bias for all four seasons (Fig. 2c). The relatively flat topography of the GCMs introduces a warmer bias as the cooler air over high mountains is not captured, for example in the Qilian Mountains (although those are not located in our study area).

There is a clear cold bias of approximately $2{ }^{\circ} \mathrm{C}$ in the source region of the YR (hereafter referred to as the source region) in the Had_R and MPI_R simulations in DJF, and a much larger cold bias in the NCC_R simulations for this high-altitude area. This cold bias is present for all seasons, but is greatest in DJF. It may be inherited from the GCMs (Had and NCC), and or be attributable to inadequate representation of physical processes (Remedio et al. 2019; Tapiador et al. 2020) such as topographic forcing and snow cover, which may be overestimated (Pang et al. 2020). A further source of this apparent bias may be related to the fact that the meteorological stations are located in valley areas and 
Table 1 Regional mean extremes (unit see Table 2) in the RF (1986-2005) and their changes for each future period relative to the RF under RCP 2.6 and RCP 8.5

\begin{tabular}{|c|c|c|c|c|c|c|c|c|}
\hline & \multicolumn{2}{|l|}{ RF } & \multicolumn{2}{|l|}{ NTP } & \multicolumn{2}{|l|}{ MTP } & \multicolumn{2}{|l|}{ FTP } \\
\hline & OBS & REMO & RCP 2.6 & RCP 8.5 & RCP 2.6 & RCP 8.5 & RCP 2.6 & RCP 8.5 \\
\hline $\mathrm{TXx}\left({ }^{\circ} \mathrm{C}\right)$ & 30.2 & 30.3 & $\mathbf{1 . 2}[0.9-1.5]$ & $1.2[1.0-1.5]$ & $\mathbf{1 . 4}[1.1-2.0]$ & $\mathbf{2 . 3}[2.3-2.4]$ & $\mathbf{1 . 4}[1.2-1.5]$ & $\mathbf{5 . 3}[4.8-5.8]$ \\
\hline $\mathrm{TNn}\left({ }^{\circ} \mathrm{C}\right)$ & -23.2 & -24.3 & $\mathbf{1 . 0}[0.7-1.5]$ & $\begin{array}{l}\mathbf{1 . 3}[-0.1 \text { to } \\
2.7]\end{array}$ & $\mathbf{2 . 3}[1.9-2.8]$ & $\mathbf{2 . 6}[2.3-2.7]$ & $1.4[0.7-2.8]$ & $6.8[6.5-7.2]$ \\
\hline FD (days) & 188.6 & 176.4 & $\begin{array}{c}-\mathbf{1 2 . 1}[-15.8 \\
\text { to }-7.8]\end{array}$ & $\begin{array}{c}\mathbf{- 1 4 . 4}[-16.8 \\
\text { to }-12.0]\end{array}$ & $\begin{array}{c}-\mathbf{1 4 . 6}[-18.9 \\
\text { to }-10.8]\end{array}$ & $\begin{array}{c}-\mathbf{2 5 . 6}[-27.9 \\
\text { to }-21.2]\end{array}$ & $\begin{array}{c}\mathbf{- 1 2 . 5}[-15.5 \\
\text { to }-11.1]\end{array}$ & $\begin{array}{l}\mathbf{- 5 2 . 5}[-60.0 \text { to } \\
-43.9]\end{array}$ \\
\hline SDII (\%) & 5.4 & 7.4 & $\begin{array}{l}-0.4[-1.4 \text { to } \\
0.4]\end{array}$ & $\begin{array}{l}1.1[-0.4 \text { to } \\
2.2]\end{array}$ & $3.2[1.7-4.3]$ & 2.9 [1.4-5.9] & $\begin{array}{l}1.2[-0.2 \text { to } \\
3.4]\end{array}$ & $\mathbf{1 1 . 2}[7.2-17.6]$ \\
\hline CDD (\%) & 58.2 & 42.1 & $\begin{array}{l}-4.4[-11.3 \text { to } \\
-1.2]\end{array}$ & $\begin{array}{l}-4.0[-10.9 \text { to } \\
1.5]\end{array}$ & $\begin{array}{l}-2.4[-4.5 \text { to } \\
-0.8]\end{array}$ & $\begin{array}{l}-7.4[-8.3 \text { to } \\
-6.4]\end{array}$ & $\begin{array}{l}0.0[-4.9 \text { to } \\
4.1]\end{array}$ & $\begin{array}{l}-3.1[-8.2 \text { to } \\
-0.7]\end{array}$ \\
\hline RX5day (\%) & 51.6 & 80.7 & $\begin{array}{l}-1.0[-2.2 \text { to } \\
1.1]\end{array}$ & $\begin{array}{l}0.8[-2.9 \text { to } \\
4.5]\end{array}$ & $2.5[0.5-5.8]$ & $\begin{array}{l}1.8[-4.8 \text { to } \\
6.0]\end{array}$ & $\begin{array}{l}0.7[-2.7 \text { to } \\
4.7]\end{array}$ & $11.8[3.4-25.3]$ \\
\hline
\end{tabular}

Simulated values are the averages of three RCMs simulations. Values in bold are statistically significant at the $95 \%$ confidence level. Values in square bracket indicate the spreads of the three REMO simulations. According to the regionally averaged value, FD is not an index to indicate an extreme event in the YRB but is still remained as a special condition due to its importance for agriculture, ecosystems, and human health

Table 2 Definition and calculation of selected six climate extreme temperature and precipitation indices

\begin{tabular}{|c|c|c|}
\hline Indices name & Definition and calculation & Unit \\
\hline TXX & $\begin{array}{l}\text { Maximum value of daily maximum temperature. Let } \mathrm{TXX}_{\mathrm{ij}} \text { be the daily maximum temperatures in month } \mathrm{i} \text {, period } \mathrm{j} \text {. } \\
\text { The maximum daily maximum temperature in period } \mathrm{j} \text { is then } \mathrm{TXx}_{\mathrm{j}}=\max \left(\mathrm{TXx}_{\mathrm{ji}}\right)\end{array}$ & ${ }^{\circ} \mathrm{C}$ \\
\hline $\mathrm{TNn}$ & $\begin{array}{l}\text { Minimum value of daily minimum temperature. Let } \mathrm{TNn}_{\mathrm{ij}} \text { be the daily minimum temperatures in month } \mathrm{i} \text {, period } \mathrm{j} \text {, } \\
\text { then the minimum daily minimum temperature in period } \mathrm{j} \text { is } \mathrm{TNn}_{\mathrm{j}}=\min \left(\mathrm{TNn}_{\mathrm{ji}}\right)\end{array}$ & ${ }^{\circ} \mathrm{C}$ \\
\hline FD & $\begin{array}{l}\text { The annual number of frost days when the absolute } \mathrm{TN} \text { (daily minimum temperature) is less than } 0{ }^{\circ} \mathrm{C} \text {. Let } \mathrm{TN}_{\mathrm{i}, \mathrm{j}} \text { be } \\
\text { daily minimum temperature on day } \mathrm{i} \text { in year } \mathrm{j} \text {, the number of days where } \mathrm{TN}_{\mathrm{i}, \mathrm{j}}<0{ }^{\circ} \mathrm{C} \text { is counted }\end{array}$ & days \\
\hline SDII & $\begin{array}{l}\text { Simple precipitation intensity index. Let } \mathrm{PR}_{\mathrm{wj}} \text { be the daily precipitation amount on wet days }(\mathrm{PR} \geq 1 \mathrm{~mm}) \text { in period } \mathrm{j} \text {. } \\
\text { If } \mathrm{W} \text { represents the number of wet days in } \mathrm{j} \text {, then } S D I I_{j}=\sum_{w=1}^{W} P R_{w j} / W\end{array}$ & $\mathrm{~mm} \mathrm{day}^{-1}$ \\
\hline CDD & $\begin{array}{l}\text { Maximum number of consecutive dry days (daily precipitation amount }<1 \mathrm{~mm} \text { ). Let } \mathrm{PR}_{\mathrm{ij}} \text { be the daily precipitation } \\
\text { amount on day } \mathrm{i} \text { in period } \mathrm{j} \text {, the largest number of consecutive days where } \mathrm{PR}_{\mathrm{ij}}<1 \mathrm{~mm} \text { is counted }\end{array}$ & days \\
\hline RX5day & $\begin{array}{l}\text { Maximum consecutive 5-day precipitation. Let } P_{k j} \text { be the precipitation amount for the 5-day interval ending on day } \\
k \text {, in period } j \text {. The maximum 5-day values for period } j \text { are } R X 5 d_{a y}=\max \left(P_{k j}\right)\end{array}$ & $\mathrm{mm}$ \\
\hline
\end{tabular}

the observation data may therefore include a warm bias for high altitude areas (Wang et al. 2016). With the exception of JJA, there are some warm biases over the rest of simulated domain. The warm biases in the MPI_R simulations can be partly attributed to the warm biases in the MPI simulations. Relative to the other seasons, the temperature difference in JJA is fairly homogeneous throughout the YRB (around $\pm 1^{\circ} \mathrm{C}$ ). The downscaled simulations have significantly weaker overall biases than the GCM simulations, but have a greater cold bias in the upper reaches, which is a high altitude area. This shows that topographic forcing and local physical processes such as snow-albedo feedback plays important roles. The overall air temperature difference between the ensemble mean (ENS) and observation data ranges from -0.1 to $1.2^{\circ} \mathrm{C}$.

For a more quantitative and systematic evaluation, we used a Taylor diagram to expound the skill of the REMO simulations (Fig. 3). All three REMO simulations successfully reproduced the spatial distribution of temperature with CCs greater than 0.90. With the exception of DJF, the CCs are greater than those in the GCM simulations, denoting the REMO improves the ability in capturing the spatial pattern of temperature. The REMO simulations are more variable than observations and the GCM simulations in all seasons, as shown by the difference in the standard deviations, and consistently reproduce JJA temperature with the greatest skill, as shown by the highest CC and smallest RMSD. Compared with the GCM simulations, the REMO simulations perform much better except in DJF, as indicated by higher CCs and smaller RMSDs. The skill of the ENSs is mixed results, with the smaller bias for JJA than the individual REMO simulations, but larger biases for some areas in some seasons. The ENSs reproduce the spatial variability in temperature throughout the YRB reasonably skillful. 


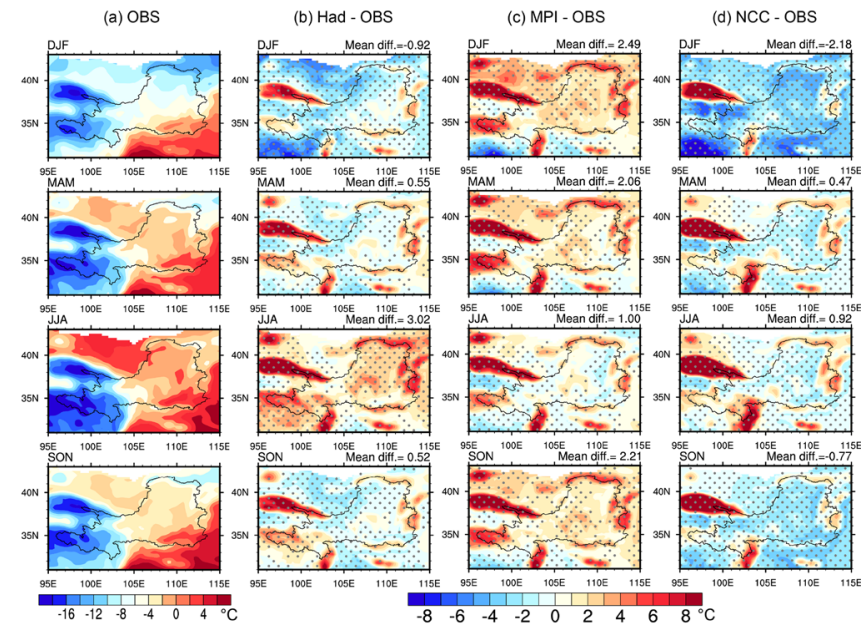

Fig. 2 a Air temperature from observations (OBS), and differences between the simulations and OBS over the YRB for the period 19762005: b-d from the GCMs, $\mathbf{e}-\mathbf{g}$ for the corresponding RCMs, $\mathbf{h}$ for the ensemble mean of the three RCM simulations. The regional mean

\subsubsection{Precipitation}

In Fig. 4, the precipitation bias, relative to the observation data, is compared for the three GCMs and for REMO forced by the three GCMs. The three GCM simulations have a significant wet bias in all four seasons with the exception of Had during JJA showing a mixture of negative and positive biases. This wet bias is greatest in the NCC simulations, and is particularly high in JJA and SON. The REMO simulations consistently overestimate precipitation for the YRB in DJF and March-May (MAM), especially for high elevation areas of the source region with complex terrain. The Had_R simulations have a wet bias in the source region but a dry bias for the rest of the study area in JJA and SON, while precipitation for these seasons is underestimated for most of the YRB in the MPI_R simulations, and there is a wet bias throughout the area for these seasons in the NCC_R simulations. The wet bias probably stems partially from overestimated precipitation for the YRB in the GCMs used to force the REMO simulations but may also be attributed to errors in REMO as it has been showed to overestimate moisture influx in ERA-Interim driven simulations (Pang et al. 2020). The wet bias may also reflect underestimated precipitation in the observation data, which were not corrected for rain gauge measurements under-catch (Wu and Gao 2013; Wang et al. 2018b) and therefore likely underestimate the real precipitation amount, particularly for solid precipitation in the cold season. The REMO simulations generally have a lower wet bias than the GCMs in the YRB and so capture precipitation more realistically. With the exception of JJA, precipitation is overestimated in the ENSs. Biases are somewhat reduced in the ENSs, relative to the individual REMO simulations.

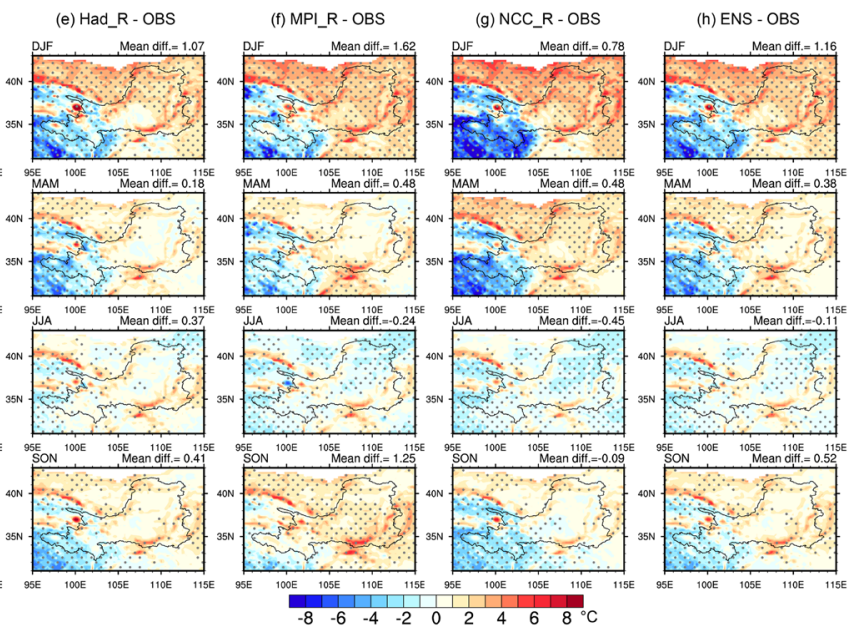

difference is marked at each upper right corner of the panel. The black dots denote differences statistically significant at the 95\% confidence level according to the two-tailed Student's $t$ test

Figure $3 \mathrm{~b}$ shows that the REMO simulated precipitation for DJF does not agree with observations at the basin scale, especially for the Had_R and NCC_R simulations, which correspond to low CCs and high spatial standard deviations when compared to the observation data. This is because these two models produce two large rainfall centers in the western YRB that do not appear in the observation data (Fig. 4). REMO simulates precipitation with greater skill for the wet season, particularly in JJA when the CC and RMSD between the simulations and observations are high and low, respectively. The MPI_R simulations reproduce precipitation with the greatest skill, corresponding to a CC ranging from 0.67 to 0.85 and a ratio of standard deviations of between 1.3 and 3.6. Overall, except in JJA, the REMO simulations show no clear improvements over the GCM runs in reproducing the spatial pattern of precipitation in terms of the ensemble means of model simulations.

The anomalous rainfall centers simulated in the western YRB (Fig. 4e, g) are likely to be related to the climate effect of lakes. Previous studies have shown that surface temperature is generally higher for a lake than for the surrounding land. A relatively warm lake surface can influence precipitation through enhanced low-level convergence and updraft over the lake, which supplies energy and moisture that can drive the development of convective precipitation (Dai et al. 2018). The bias associated with this is smaller for the MPI_R simulations than for the other two REMO simulations, possibly because the air temperature in the MPI simulations are warmer than in the other two GCMs, making air and lake temperatures more similar and reducing the lake effect on precipitation, relative to the other simulations. 
(a) Air temperature

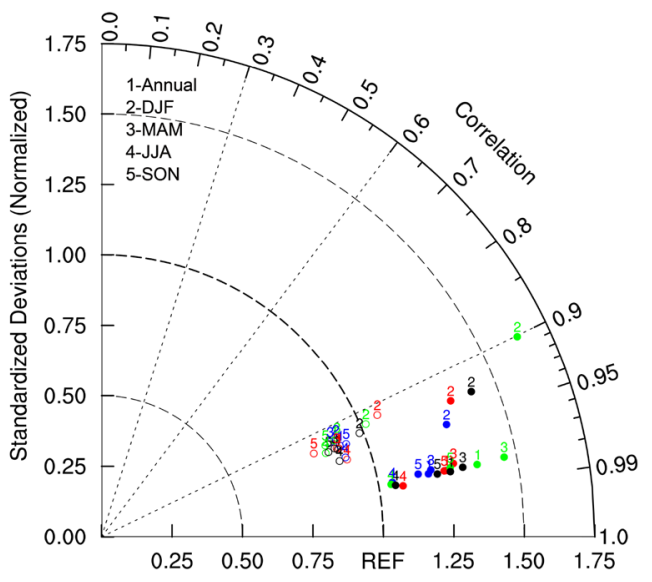

(c) Extreme indices for temperature

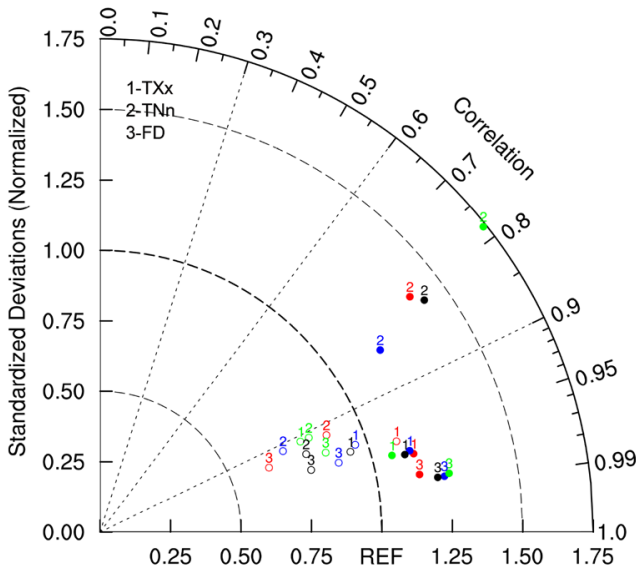

Fig. 3 Taylor diagram for the spatial variability of annual and seasonal mean a air temperature and $\mathbf{b}$ precipitation and $\mathbf{c}$, $\mathbf{d}$ their extreme indices. The radial distance from the origin is the ratio between the simulated and observed standard deviation for temperature and precipitation. The azimuthal position is the correlation coef- (b) Precipitation

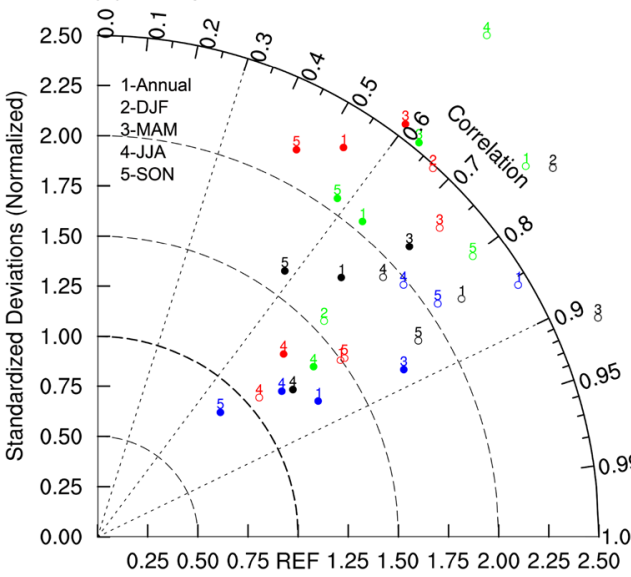

(d) Extreme indices for precipitation

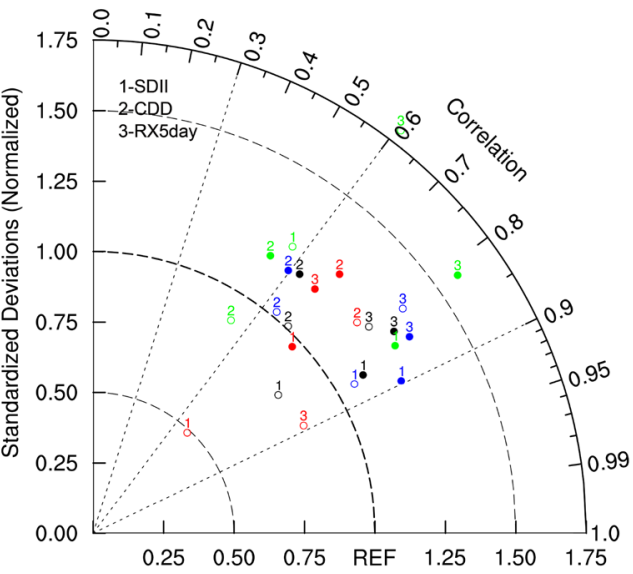

- $\mathrm{Had}$
- MPI
$-\mathrm{NCC}$

- ENS_GCM

- Had R

- MPI_R

- NCC R

- ENS

ficient between the simulations and observations. The distance from the REF point indicates the normalized centered RMSE. REF is the CN05.1 data set. ENS_GCM and ENS denote the ensemble mean of the three GCM and REMO simulations, respectively. The numbers denote seasons in $\mathbf{a}, \mathbf{b}$ and extreme climate indices in $\mathbf{c}, \mathbf{d}$

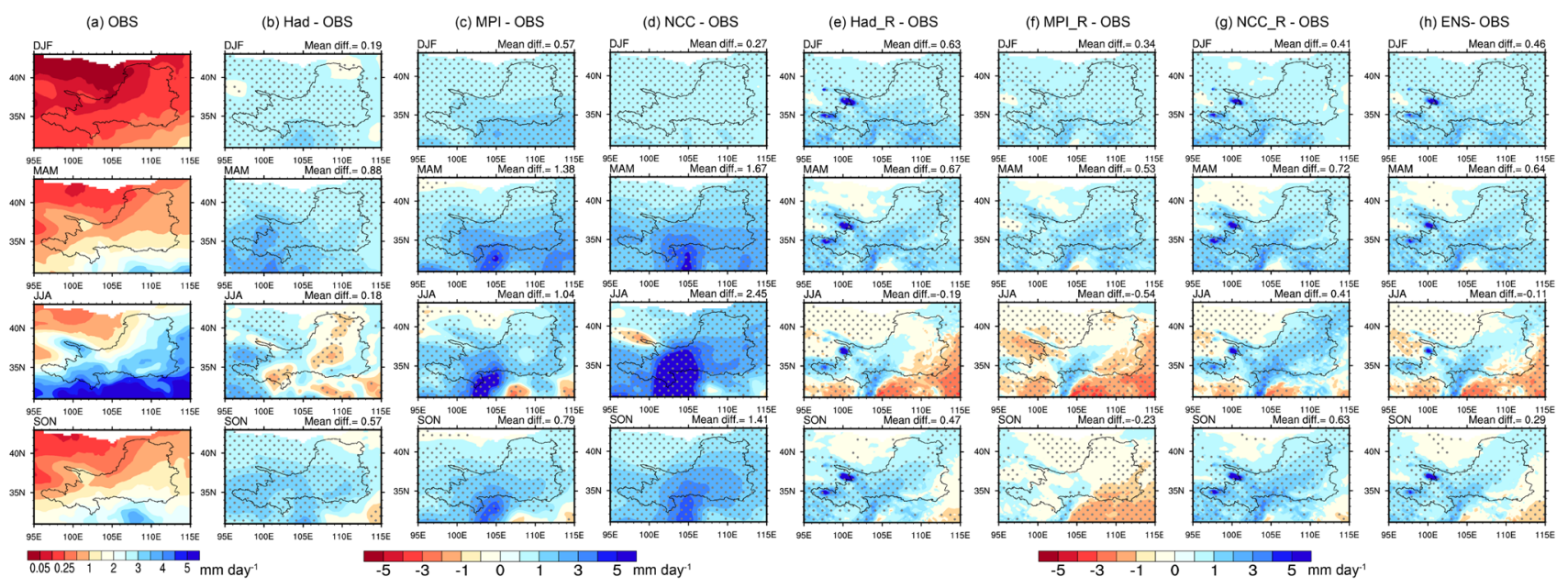

Fig. 4 As Fig. 2, but for precipitation 


\subsubsection{Climate extreme indices}

Figure 5 shows the observed and simulated extreme temperature indices over the YRB for the historical period 1976-2005. Both TXx and TNn decrease with altitude and FD increases with altitude in both the observations and the simulations. The highest TXx value is over $30^{\circ} \mathrm{C}$, which occurs in the middle reaches of the YRB where altitudes are relatively low (Fig. 5a). The simulated values are higher than the observations for the middle reaches of the YRB. $\mathrm{TNn}$ is low in high altitude areas, and the simulated TNn values are much lower than the observations for the source region (Fig. 5b). Values for FD are high for the source region, where they exceed 240 days (Fig. 5c). FD values are underestimated in the middle reaches by the three models (Fig. 5d), which may be due to the warm bias in the REMO simulations. The REMO simulations overestimate FD in the source region by up to around 40 days, which follows from the cold temperature bias. The ENSs for the simulations reproduce the spatial pattern of the extreme temperature indices well and reduce some model biases, relative to the individual simulations. The high CC values $(>0.78)$ in the Taylor diagram (Fig. 3c) show that spatial patterns for the extreme temperature indices are simulated by REMO well. The standard deviation for the REMO simulated temperature indices is much higher than for the observed and the GCM simulated values, especially for $\mathrm{TNn}$, indicating greater spatial variability in the REMO simulations. In general, the GCM simulations produce lower spatial CCs and higher RMSDs for temperature indices except for TNn than the REMO simulations, suggesting the downscaled simulations show evident advantage over the GCM runs in reproducing TXX and FD.

There is a clear latitudinal gradient in the observed extreme precipitation indices (Fig. 6), which is consistent with the observed precipitation pattern. Values for SDII and (a) TXX
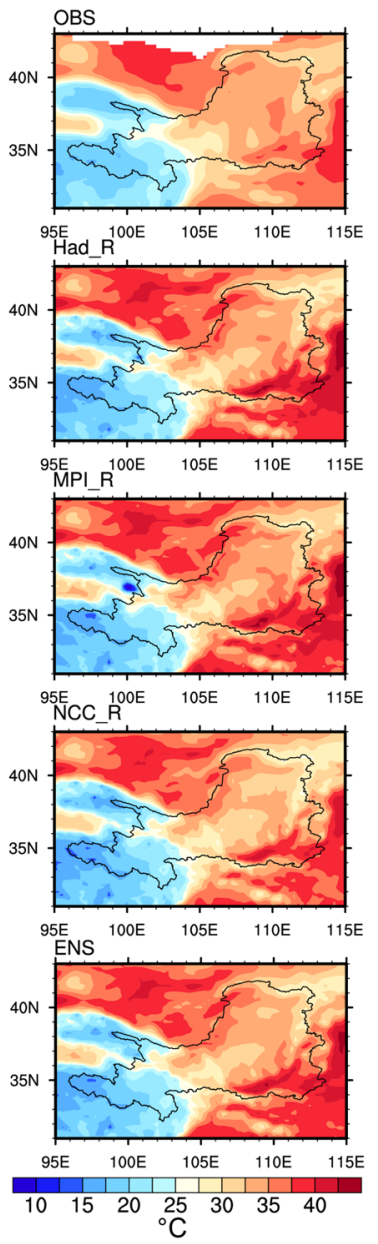

(b) TNn
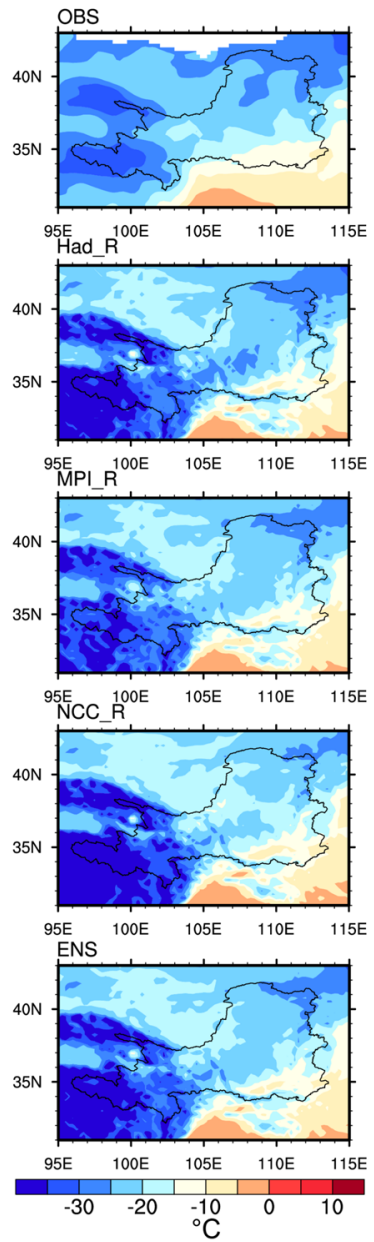

(c) FD
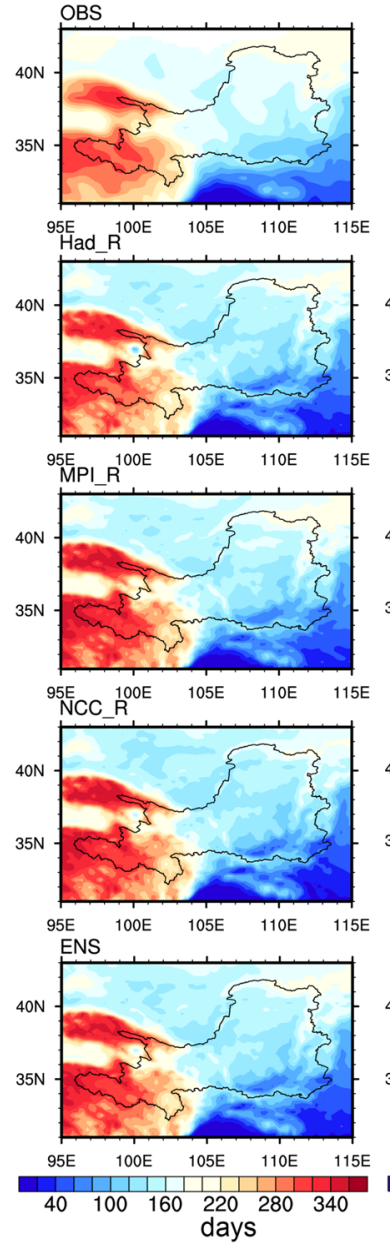

(d) FD
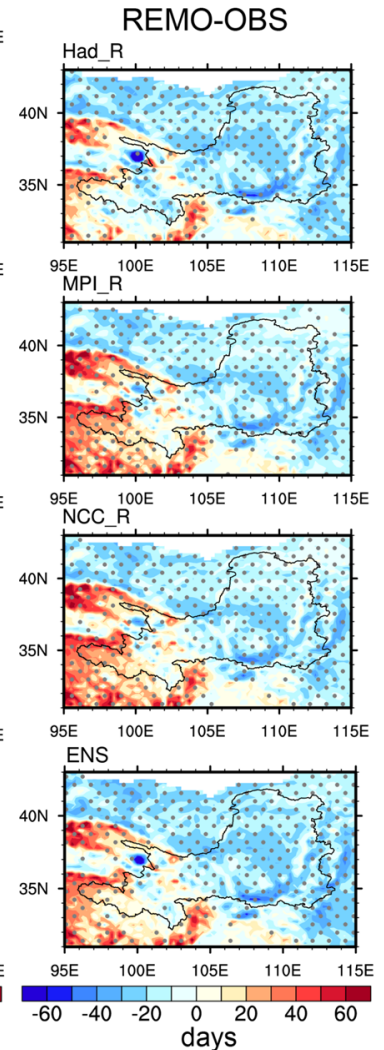

Fig. 5 Spatial distributions of the extreme temperature indices from OBS, Had_R, MPI_R, and NCC_R over the YRB during the period 1976-2005. The differences in FD between the model simulation and
OBS are shown in the last column. The black dots denote differences statistically significant at the $95 \%$ confidence level according to the two-tailed Student's $t$ test 
RX5day decrease from southeast to northwest in the YRB, while values for CDD increase gradually. All the REMO simulations successfully capture the spatial distribution of extreme precipitation indices, with CC values for SDII that exceed 0.73 (Fig. 3d). However, SDII is overestimated by approximately $1.0-2.0 \mathrm{~mm} \mathrm{day}^{-1}$ in all the simulations. The standard deviations for the simulated SDII values are greater than one, except for Had_R, which suggests that REMO overestimates spatial variability for SDII. The drought index, CDD, has an observed value of 58 days in the YRB on average. The models reproduce the general patterns for CDD, with CC values greater than 0.54 between NCC_R and the observations, although the Had_R simulations underestimate CDD in the southern YRB. There is a wide inter-model spread in REMO simulated RX5day values (Fig. 3d), which are overestimated in all three REMO simulations, notably in the southeastern YRB (Fig. 6c). Discrepancies between simulated and observed extreme precipitation indices are in accord with the wet bias in the simulations that was discussed earlier (Fig. 4). Again, large biases are seen for the (a) SDII
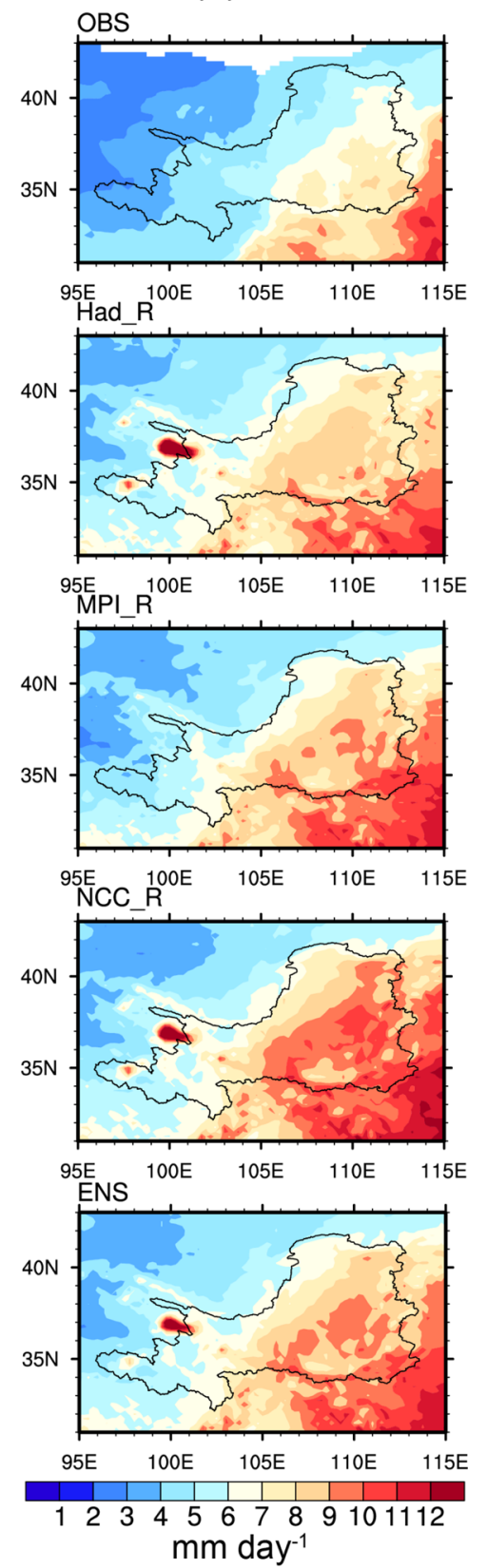

(b) CDD
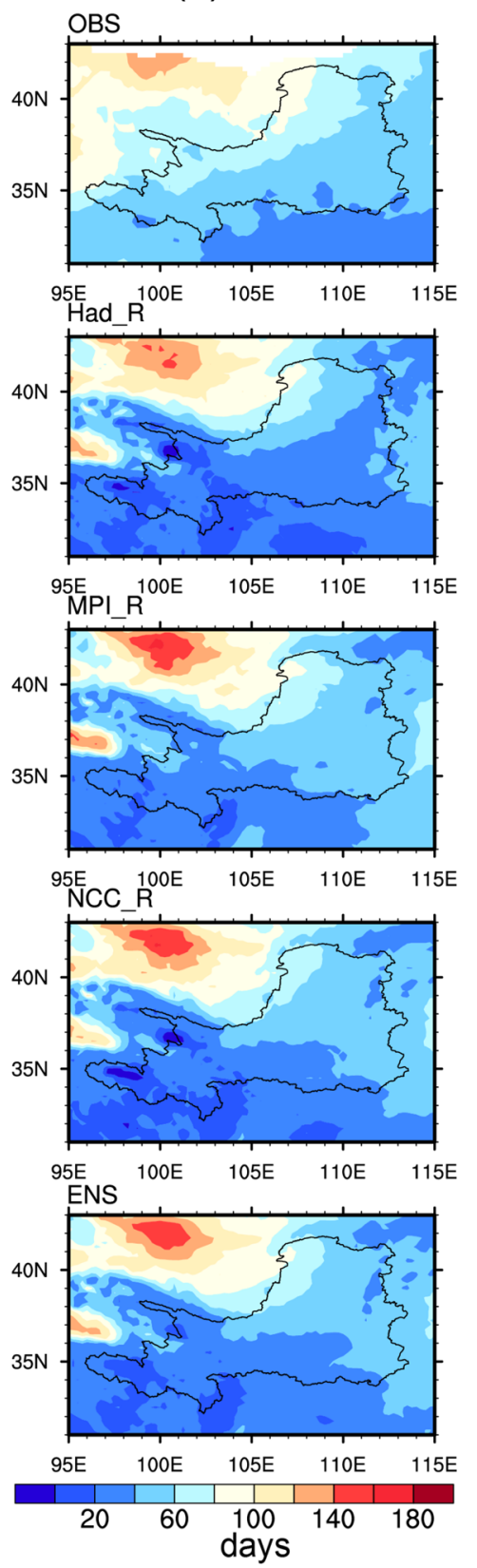

(c) RX5day
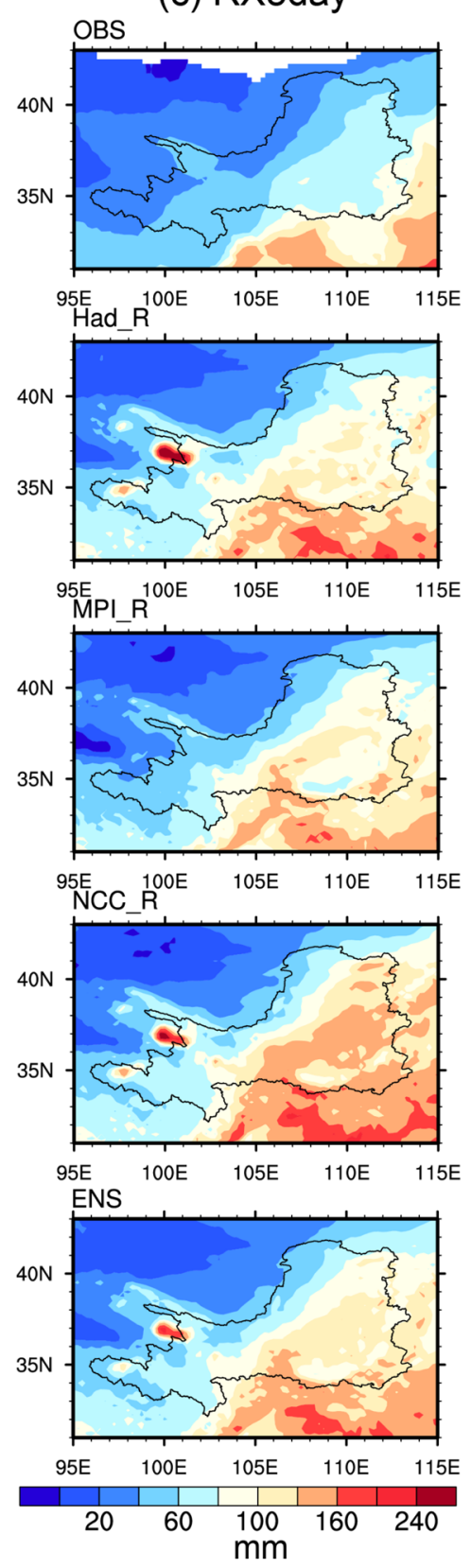

Fig. 6 As Fig. 5, but for the extreme precipitation indices 
lakes in the western part of the domain as also discussed for average precipitation (Fig. 4). For SDII and RX5day, the REMO simulations outperform the GCM simulations, as indicated by high CCs and small RMSDs for the ENSs and individual REMO simulations (except for Had_R in simulating RX5day).

To summarize, the REMO simulations are generally in agreement with the observed mean and extreme, although some significant biases exist. Temperature is captured more realistically than precipitation in the simulations. The ability of REMO to reproduce temperature and precipitation climatologies varies spatially and temporally over the YRB. The ENSs outperform most of the individual model simulations of historical climate, and the analysis of future climate presented in the next section therefore mainly focuses on projections from the ENSs. The projections from the three REMO simulations are also provided in the supplementary materials (Figs. S1-S9), meanwhile, the similarities and differences among the models are discussed in the text to enrich the projection results.

\subsection{Projected future climate changes}

\subsubsection{Changes in air temperature}

Seasonal temperature differences between three future periods and the RF are shown in Fig. 7 for the ENS projections, with two assumed RCP scenarios. Under RCP 2.6, temperature increases in the YRB are more significant in high altitude areas in DJF and are spatially homogenous in JJA. Relative to temperatures in the $\mathrm{RF}$, the increase is greatest for the MTP, when it reaches $1.5-2.0{ }^{\circ} \mathrm{C}$ (Fig. 7b), despite the peak in GHG emissions occurring between 2010 and 2020 in RCP 2.6, and the concentrations continue to increase implying the peak in forcing is later (2030s-2040s). The magnitude of the warming decreases thereafter as GHG emissions decrease.

For the NTP, warming under RCP 8.5 is similar to warming under RCP 2.6 in the YRB, with differences between the two ranging from -0.5 to $0.5{ }^{\circ} \mathrm{C}$ (Fig. 7d). Unsurprisingly, a significant rise in temperature results from the increasing GHG emissions in the FTP under RCP 8.5, particularly in the source region. Compared to temperatures in the RF, the regional average temperature would significantly increase by $5.6^{\circ} \mathrm{C}$ in DJF, by $4.9{ }^{\circ} \mathrm{C}$ in MAM, by $5.3{ }^{\circ} \mathrm{C}$ in JJA, and by $5.4^{\circ} \mathrm{C}$ in SON by the end of twenty first century under high emissions scenario RCP 8.5 (Table 3). In the FTP, mean annual temperatures would be $5.3^{\circ} \mathrm{C}$ higher than in the $\mathrm{RF}$, with a spread of $4.3-6.6{ }^{\circ} \mathrm{C}$.

There are spatial and temporal differences in the magnitude of the warming projected by the individual model simulations and Had_R generally simulates a stronger warming than MPI_R or NCC_R. The highest spread for the projected warming is for SON under RCP 8.5 for the FTP (Table 3). All three models simulate remarkably consistent and notable
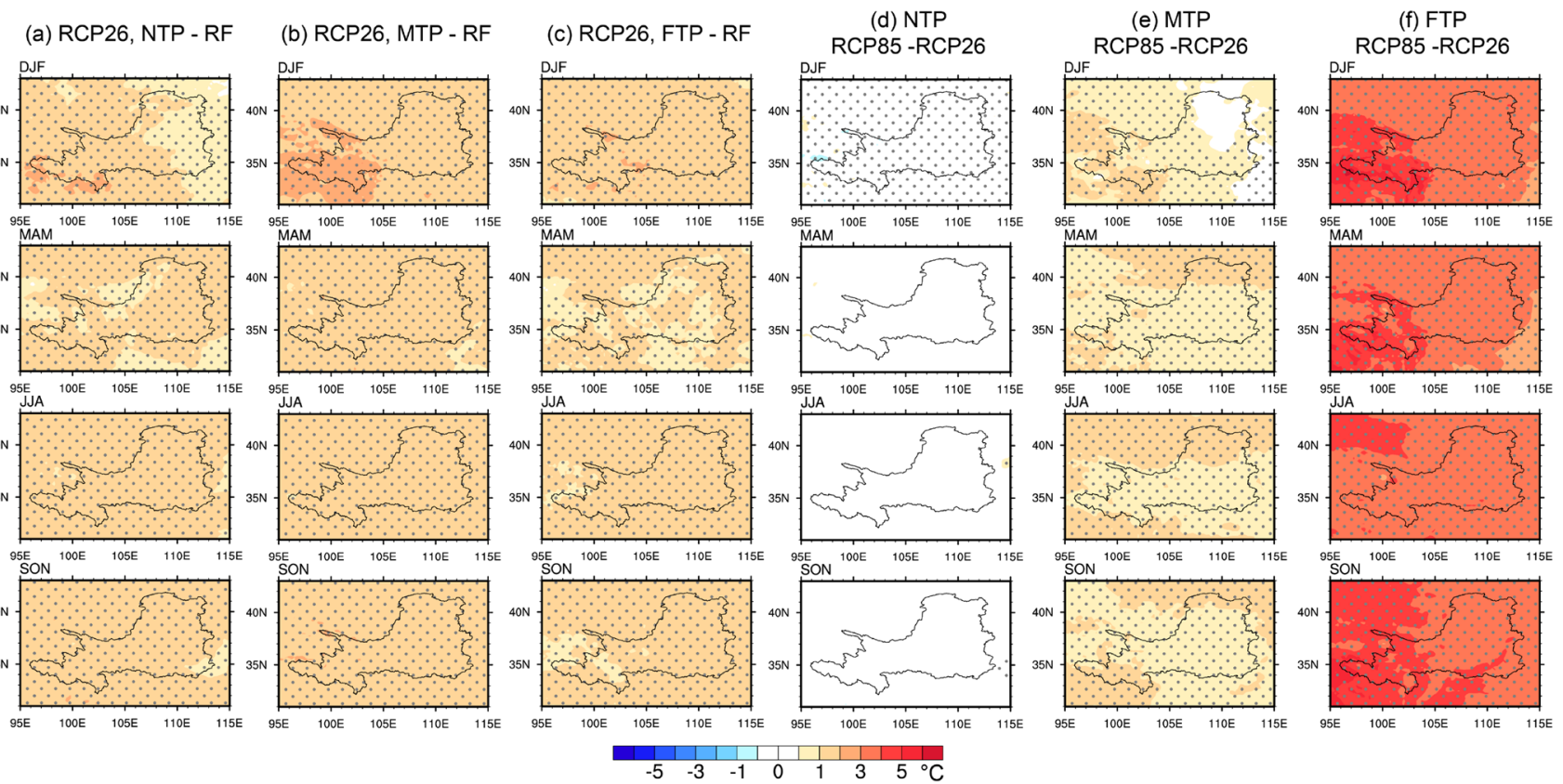

Fig. 7 Projected changes in seasonal air temperature for the NTP (2021-2040), MTP (2041-2060), and FTP (2081-2100), relative to the RF (1986-2005) under RCP 2.6 and differences in temperature between RCP 8.5 and RCP 2.6 for the same periods using the average

of the three REMO simulations. The black dots denote differences statistically significant at the $95 \%$ confidence level according to the two-tailed Student's $t$ test 
warming under both RCP 2.6 and RCP 8.5, with significant increases in the source region under RCP 8.5 (Figs. S1-S3).

Monthly mean temperatures would increase with increasing GHG emissions, but the temperature difference, relative to the RF, would be greatest in the winter months under RCP 8.5 (Fig. 8a). Under low emissions scenario RCP 2.6, temperatures would decrease somewhat (by $0.2{ }^{\circ} \mathrm{C}$ in MAM, at a confidence level exceeding $95 \%$ ) by the end of this century relative to the MTP, which follows the trajectory of the applied radiative forcing in RCP 2.6 (Meinshausen et al. 2011). Monthly temperature increases under RCP 2.6 are less rapid than under RCP 8.5 for all the three future periods.

\subsubsection{Changes in precipitation}

Figure 9 shows the projected changes in seasonal mean precipitation for the NTP, MTP, and FTP, relative to the RF under the RCP 2.6 and RCP 8.5 scenarios. The ENS results show increases in DJF and under both RCP scenarios, although the precipitation amount remains small. The increases occur mainly in the middle reaches of the YRB. Under RCP 2.6, precipitation across the YRB can be 17\% higher than in the RF by the middle of the century (Table 3 ), while increases under RCP 8.5 are greater and can be $34 \%$ higher than in the RF by the end of the century. For MAM, changes are mostly small and insignificant under RCP 2.6, however, there is a fraction of significant increase in the midcentury. Under RCP 8.5, a gradual increase in precipitation is projected throughout the century. A patchy spatial pattern is simulated across the YRB for precipitation changes in
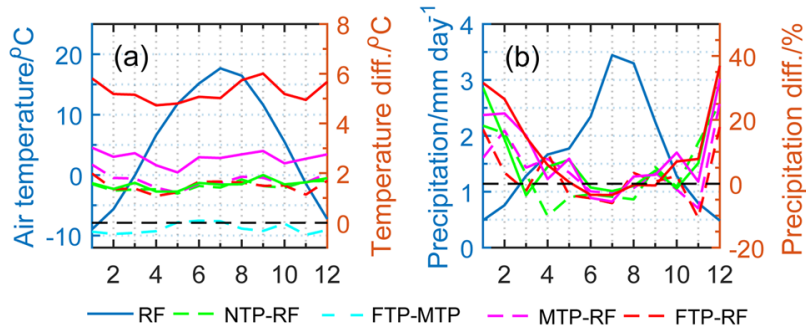

Fig. 8 Annual air temperature and precipitation cycles over the YRB for the RF (blue lines and left axis) and monthly changes (right axis) in a temperature and $\mathbf{b}$ precipitation for the NTP, MTP, and FTP, relative to the RF under RCP 2.6 (dash lines) and under RCP 8.5 (solid lines). The black dashed line denotes the zero-reference line corresponding to the right axis

JJA and SON under RCP 8.5, including small increases and small decreases. The projected change to regional average precipitation in JJA is a decrease under both RCP 2.6 and RCP 8.5, but this is not significant at the $95 \%$ confidence level. Precipitation in SON is projected to decrease slightly under RCP 2.6 but to increase under RCP 8.5. Under RCP 8.5 , precipitation is projected to decrease by $2.4 \%$ in JJA, and to increase by $3.2 \%$ in SON by the end of the century (Table 3).

The three REMO model simulations are consistent in projecting increases in precipitation in DJF (Figs. S4-6). Among the three simulations, more DJF precipitation is simulated by NCC_R for the NTP under RCP 2.6 and for the FTP under RCP 8.5. In the Had_R simulations, precipitation increases in DJF and SON for the NTP are higher under

Table 3 Regional mean air temperature $\left({ }^{\circ} \mathrm{C}\right)$ and precipitation $\left(\mathrm{mm} \mathrm{day}^{-1}\right)$ in the RF (1986-2005) from OBS and the average of the three simulations and their changes (Tair: ${ }^{\circ} \mathrm{C}$, Prec: \%) for each future period and each season relative to the RF under RCP 2.6 and RCP 8.5 scenarios

\begin{tabular}{|c|c|c|c|c|c|c|c|c|c|}
\hline \multirow[t]{2}{*}{ Season } & \multirow[t]{2}{*}{ Variable } & \multicolumn{2}{|l|}{$\mathrm{RF}$} & \multicolumn{2}{|l|}{ NTP } & \multicolumn{2}{|l|}{ MTP } & \multicolumn{2}{|l|}{ FTP } \\
\hline & & OBS & REMO & RCP 2.6 & RCP 8.5 & RCP 2.6 & RCP 8.5 & RCP 2.6 & RCP 8.5 \\
\hline \multirow[t]{2}{*}{ DJF } & Tair & -7.8 & -7.3 & $\mathbf{1 . 5}[1.0-2.4]$ & $\mathbf{1 . 5}[1.0-1.9]$ & 2.0 [1.4-2.9] & $\mathbf{2 . 8}[2.4-3.6]$ & $\mathbf{1 . 5}[0.7-2.3]$ & $\mathbf{5 . 6}[4.7-6.6]$ \\
\hline & Prec & 0.2 & 0.6 & $19.1[9.7-26.9]$ & $\begin{array}{l}25.0[15.2- \\
49.9]\end{array}$ & $\begin{array}{l}17.0[12.6- \\
22.4]\end{array}$ & $\begin{array}{l}\mathbf{2 6 . 3}[19.8- \\
31.7]\end{array}$ & $\begin{array}{l}\mathbf{1 1 . 4}[-0.5 \text { to } \\
22.8]\end{array}$ & $33.7[29.3-37.6]$ \\
\hline \multirow[t]{2}{*}{ MAM } & Tair & 6.3 & 6.1 & $\mathbf{1 . 3}[0.8-2.1]$ & $\mathbf{1 . 4}[0.9-2.4]$ & $\mathbf{1 . 5}[1.0-2.4]$ & $2.4[1.8-3.1]$ & $\mathbf{1 . 2}[0.8-1.9]$ & $4.9[4.0-6.1]$ \\
\hline & Prec & 0.9 & 1.6 & $\begin{array}{l}-4.3[-10.2 \text { to } \\
\quad-1.2]\end{array}$ & $3.7[-3.0-11.6]$ & $\begin{array}{l}5.4[-6.2 \text { to } \\
10.9]\end{array}$ & $7.6[0.9-11.5]$ & $\begin{array}{l}1.4[-0.1 \text { to } \\
3.2]\end{array}$ & $\begin{array}{l}6.2[-2.9 \text { to } \\
13.9]\end{array}$ \\
\hline \multirow[t]{2}{*}{ JJA } & Tair & 17.2 & 16.4 & $\mathbf{1 . 5}[1.1-2.3]$ & $\mathbf{1 . 6}[1.2-2.1]$ & $\mathbf{1 . 7}[1.2-2.7]$ & $\mathbf{2 . 7}[2.3-3.2]$ & $\mathbf{1 . 6}[1.2-2.3]$ & $\mathbf{5 . 3}[4.5-6.3]$ \\
\hline & Prec & 2.7 & 3.0 & $\begin{array}{l}-4.2[-5.6 \text { to } \\
-1.3]\end{array}$ & $\begin{array}{l}-1.4[-2.8 \text { to } \\
-0.8]\end{array}$ & $\begin{array}{l}-2.2[-5.9 \text { to } \\
3.2]\end{array}$ & $\begin{array}{l}-2.4[-7.0 \text { to } \\
4.2]\end{array}$ & $\begin{array}{l}-2.3[-8.2 \text { to } \\
5.1]\end{array}$ & $\begin{array}{l}-2.4[-10.0 \text { to } \\
13.1]\end{array}$ \\
\hline \multirow[t]{2}{*}{ SON } & Tair & 5.2 & 5.3 & $1.5[0.8-2.6]$ & $1.7[1.0-2.7]$ & $1.7[1.1-2.7]$ & $2.6[1.8-3.7]$ & $1.4[0.9-2.3]$ & $5.4[4.1-7.1]$ \\
\hline & Prec & 1.1 & 1.4 & $4.8[0.8-11.3]$ & $\begin{array}{l}2.9[-4.3 \text { to } \\
16.7]\end{array}$ & $\begin{array}{l}-0.2[-7.9 \text { to } \\
11.3]\end{array}$ & $4.5[1.3-12.3]$ & $\begin{array}{l}-0.9[-4.0 \text { to } \\
6.1]\end{array}$ & $3.2[-8.4$ to 7.3$]$ \\
\hline \multirow[t]{2}{*}{ Annual } & Tair & 5.2 & 5.1 & $1.5[0.9-2.3]$ & $\mathbf{1 . 6}[1.2-2.3]$ & $1.7[1.2-2.7]$ & $2.6[2.1-3.4]$ & $1.5[1.0-2.2]$ & $\mathbf{5 . 3}[4.3-6.6]$ \\
\hline & Prec & 1.2 & 1.7 & $\begin{array}{l}-0.2[-1.9 \text { to } \\
2.0]\end{array}$ & $3.0[1.9-5.8]$ & $1.7[1.2-2.8]$ & $3.8[1.5-6.4]$ & $\begin{array}{l}0.1[-4.7 \text { to } \\
4.5]\end{array}$ & $\begin{array}{l}3.8[-4.8 \text { to } \\
14.7]\end{array}$ \\
\hline
\end{tabular}

Bold values indicate statistically significant at the $95 \%$ confidence level. Values in square brackets indicate the spreads of the three REMO simulations 
(a) RCP26, NTP - RF
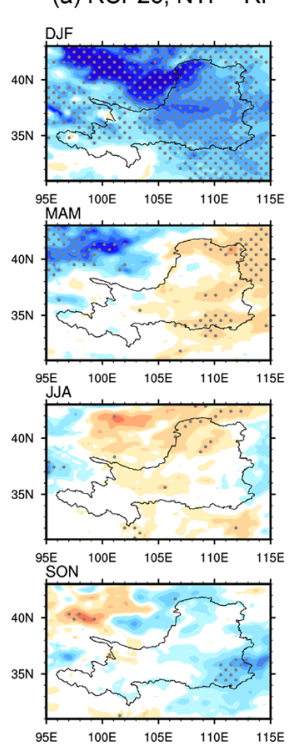

(b) RCP26, MTP - RF
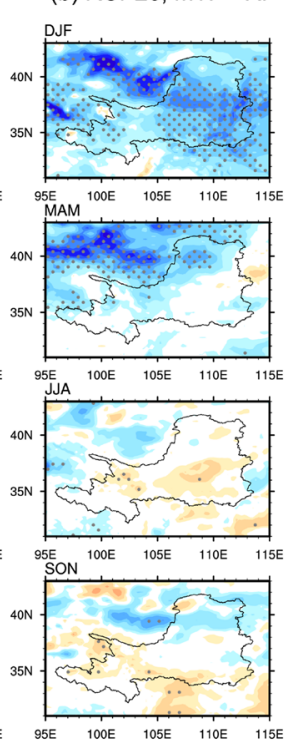

(c) RCP26, FTP - RF
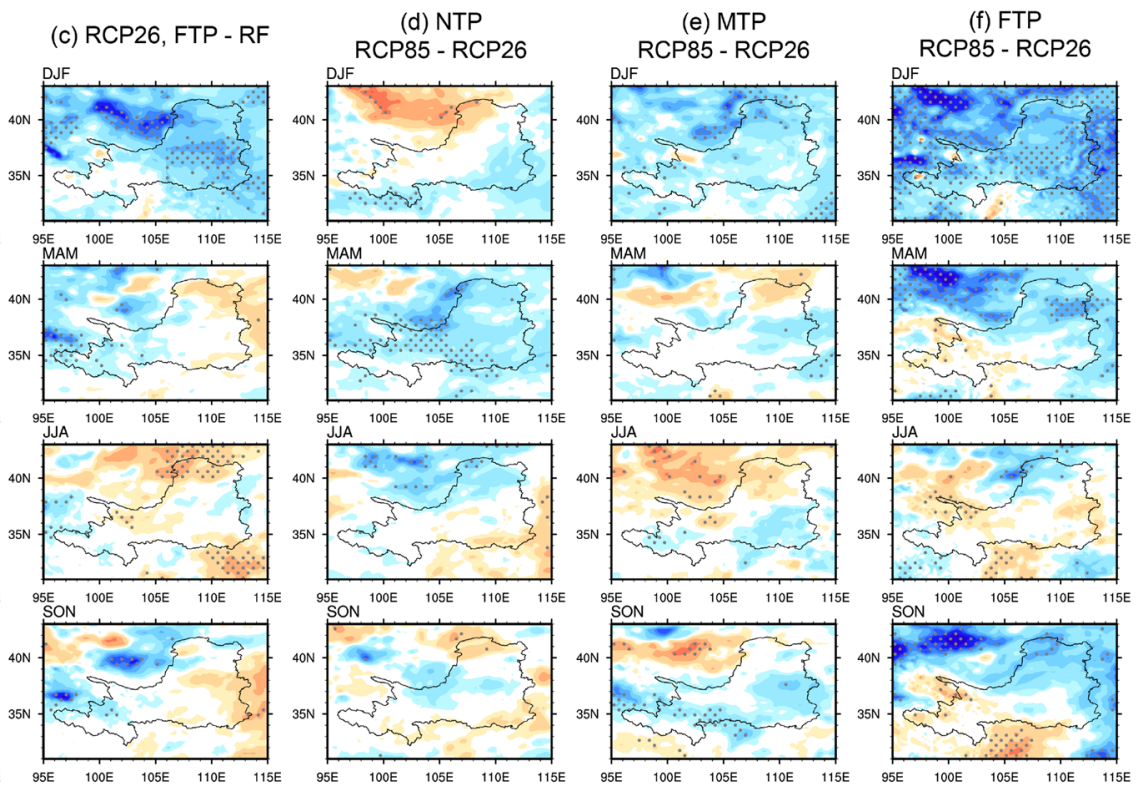

Fig. 9 As Fig. 7, but for precipitation

RCP 2.6 than under RCP 8.5, whereas precipitation in the MPI_R and NCC_R simulations is higher for the NTP under RCP 8.5 than under RCP 2.6, with the exception of JJA. Decreases in precipitation are projected in JJA and SON for the FTP in the MPI_R simulations under RCP 8.5. There are large spreads associated with the three precipitation simulations, particularly in JJA and SON, including spread over the sign of the change, i.e., whether precipitation will increase or decrease.

Figure $8 \mathrm{~b}$ shows the changes in monthly mean precipitation for the three future periods under the two emissions scenarios. Precipitation is projected to increase strongly for winter and spring months under RCP 8.5. In agreement with results discussed above, precipitation between March and August is projected be lower in the NTP than in the RF under RCP 2.6, and to be slightly lower for June and July in the MTP and FTP than in the RF under RCP 8.5. These suggest that the annual cycle of precipitation will likely decrease due to the significant increase in precipitation amount in dry season instead of wet season.

Changes to precipitation variability may provide triggers for extreme events such as floods and droughts. Figure 10 shows the projected changes in the interannual variability for precipitation, presented as the changes in standard deviation for seasonal precipitation for the NTP, MTP, and FTP, relative to the RF. There are clear increases in the standard deviation for precipitation over most of the YRB in DJF and some patchy increases in MAM under RCP 2.6. Changes in the variability for JJA and SON are mostly decreases, but these are not significant at the $95 \%$ confidence level. Under
RCP 8.5, model results show large increases in the standard deviation for precipitation over most of the YRB, with DJF exceeding the $95 \%$ confidence level, although there are some decreases in SON for the NTP and MTP. This shows that interannual precipitation variability, particularly in DJF, changes markedly in response to warming, which is likely to lead to significant changes in precipitation extremes.

\subsubsection{Changes in extreme climate indices}

Changes projected under RCP 2.6 for the three extreme temperature and precipitation indices for the three future periods, relative to the RF, are shown in Fig. 11. Along with the mean temperature increases, TXx and TNn increase consistently, by an average of $1.2{ }^{\circ} \mathrm{C}$ and $1.0{ }^{\circ} \mathrm{C}$ for the NTP, respectively (Table 1 ). In the MTP, the increase in TNn is higher than that in TXx over most of the YRB. Under RCP 2.6, FD is projected to gradually decrease and peak for the MTP (Fig. 11e; Table 1). Changes to the extreme temperature indices are projected to be much larger under RCP 8.5 than under RCP 2.6. Significant increases in TXx and TNn are projected for the mid and late twenty first century, and decreases are projected for FD. Increases in TXx under RCP 8.5 resemble those of under RCP 2.6, but with a higher increase for the FTP under RCP 8.5. The TNn increases are projected for the whole region, particularly for the source region and eastern YRB in the FTP. Under RCP 8.5, the magnitude of the increase in TNn is greater than the increase in TXx for each of these future periods, with an average increase of $5.3{ }^{\circ} \mathrm{C}$ and $6.8{ }^{\circ} \mathrm{C}$ for $\mathrm{TXx}$ and $\mathrm{TNn}$ in the late 
(a) RCP26, NTP-RF

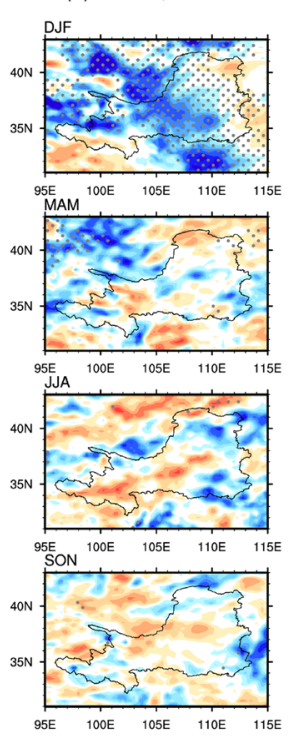

(b) RCP26, MTP-RF
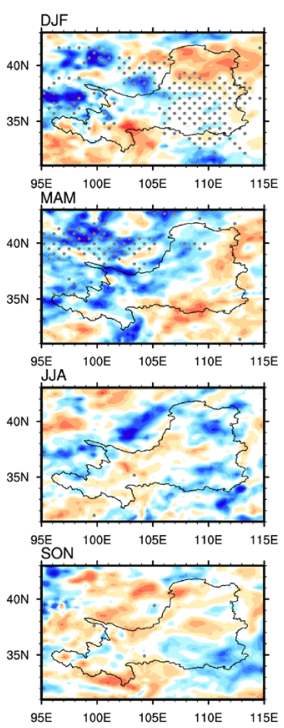

(c) RCP26, FTP-RF
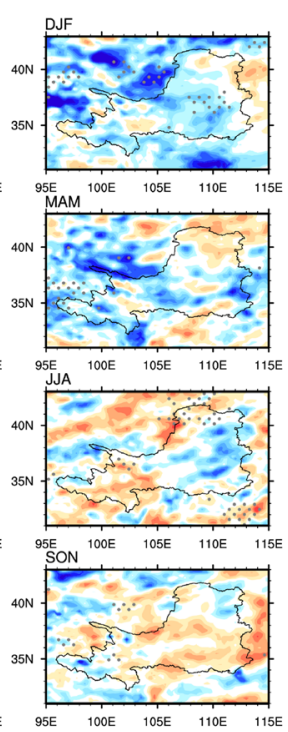

(d) RCP85, NTP-RF
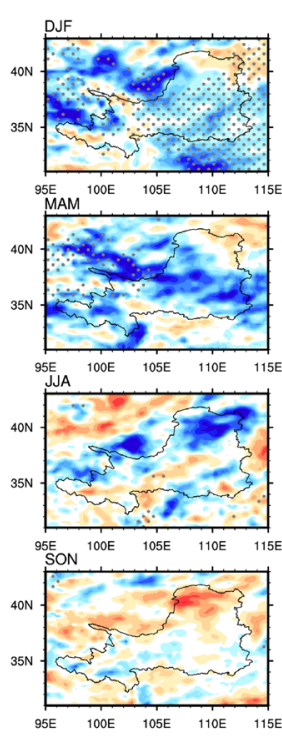

(e) RCP85, MTP-RF
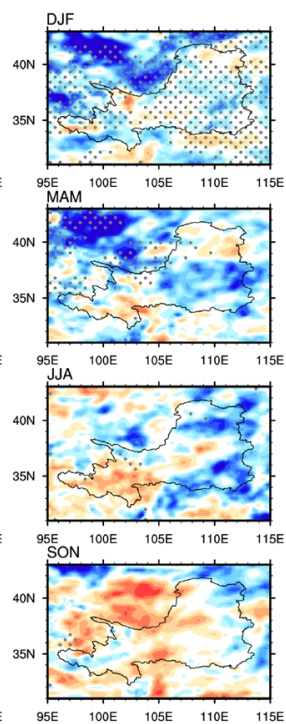

(f) RCP85, FTP-RF
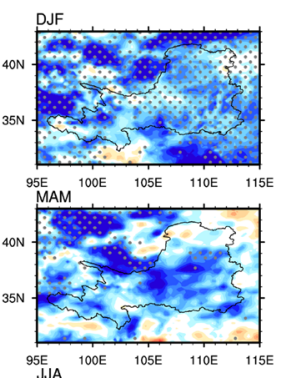
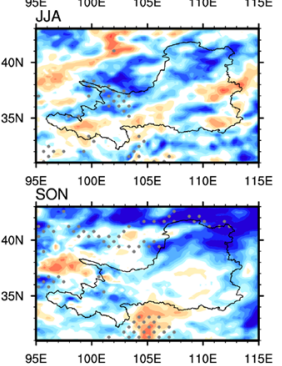

$\begin{array}{llllllllllll}-100 & -60 & -40 & -20 & 0 & 20 & 40 & 60 & 100 \%\end{array}$

Fig. 10 Projected changes in the standard deviation for seasonal precipitation for the NTP (2021-2040), MTP (2041-2060), and FTP (2081-2100), relative to the RF (1986-2005) under RCP 2.6 and RCP
8.5 according to the average of the three REMO simulations. The black dots denote differences statistically significant at the $95 \%$ confidence level according to the two-tailed Student's $t$ test twenty first century, relative to the RF. The regionally averaged increases in TXx and TNn for the YRB in the FTP under RCP 8.5 are comparable to the average increase projected over all of China from RegCM4 simulations driven by HadGEM2-ES (Shi et al. 2018). More intense decreases in $\mathrm{FD}$ also in the source region than in other areas. Under RCP 8.5 , the regionally averaged decrease in FD is approximately 53 days by the end of twenty first century, which is twice the decrease of 26 days for the MTP (Table 1).

As for extreme precipitation indices, SDII is projected to increase, exceeding $0.5 \mathrm{~mm} \mathrm{day}^{-1}$ under RCP 8.5 by the end of the century, with the largest increase occurs in the middle reaches (Fig. 11h). Under high emissions scenario RCP 8.5, SDII is projected to significantly increase by $3 \%$ and $11 \%$ for the MTP and FTP in the YRB (Table 1). The projected increase in precipitation intensity is generally in accord with the theory that precipitation increases with rising temperature, following the Clausius-Clapeyron equation (Trenberth 2011). The decline in CDD is projected to weaken and then to become an increase for the FTP under RCP 2.6 (Fig. 11i). Under RCP 8.5, CDD would continue to significantly decrease, reaching a minimum for the MTP, and then remaining lower for the FTP, meaning that drought would be less persistent in the YRB. Under RCP 2.6, RX5day is projected to decrease slightly for most of the region, but to increase for the middle reaches (Fig. 11k). Under RCP 8.5, the projection exhibits a strong increase for the FTP (by 12\%, significant at the $95 \%$ confidence level) throughout most of the YRB. These increases in extreme precipitation, in terms of rain intensity and rain events, are likely to increase flood risk.

The discrepancies between the changes projected for extreme temperature events exist in the three REMO simulations (Figs. S7-9). For example, the amplitude and spatial distribution of changes to TNn in the NTP are different: there are some decreases in the Had_R simulations under RCP 8.5, while there is a clear increase in the NCC_R simulations. The three simulations all display significant decreases in FD for the upper reaches. The magnitude of changes simulated under RCP 8.5 for the FTP differs between the simulations, but the simulated trends converge.

With regard to the projected extreme precipitation indices (Figs. S7-9), under RCP 8.5, Had_R simulates the largest increases for SDII and RX5day and MPI_R simulates the strongest decrease for CDD. The spread between the three simulations shows that large uncertainties should be associated with the extreme precipitation event simulations. However, as integration time and emissions increase, the tendencies for the indices simulated by the different models become consistent, with positive changes for SDII and RX5day and negative changes for CDD for the FTP, relative to the RF. 

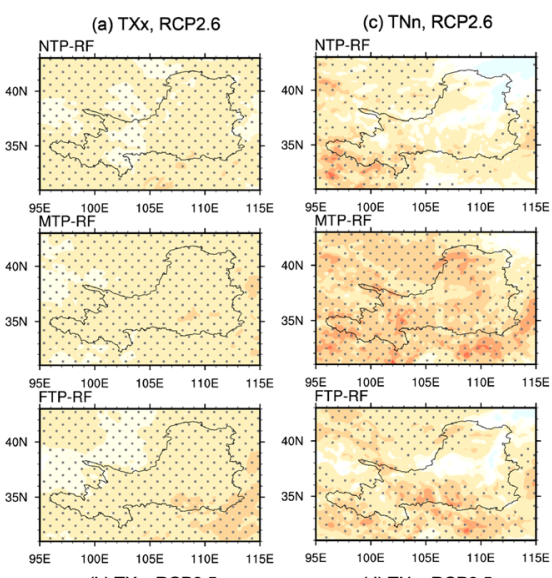

(b) TXX, RCP8.5

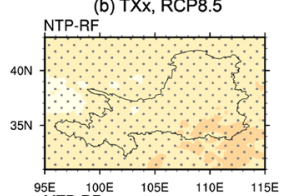

(d) TNn, RCP8.5
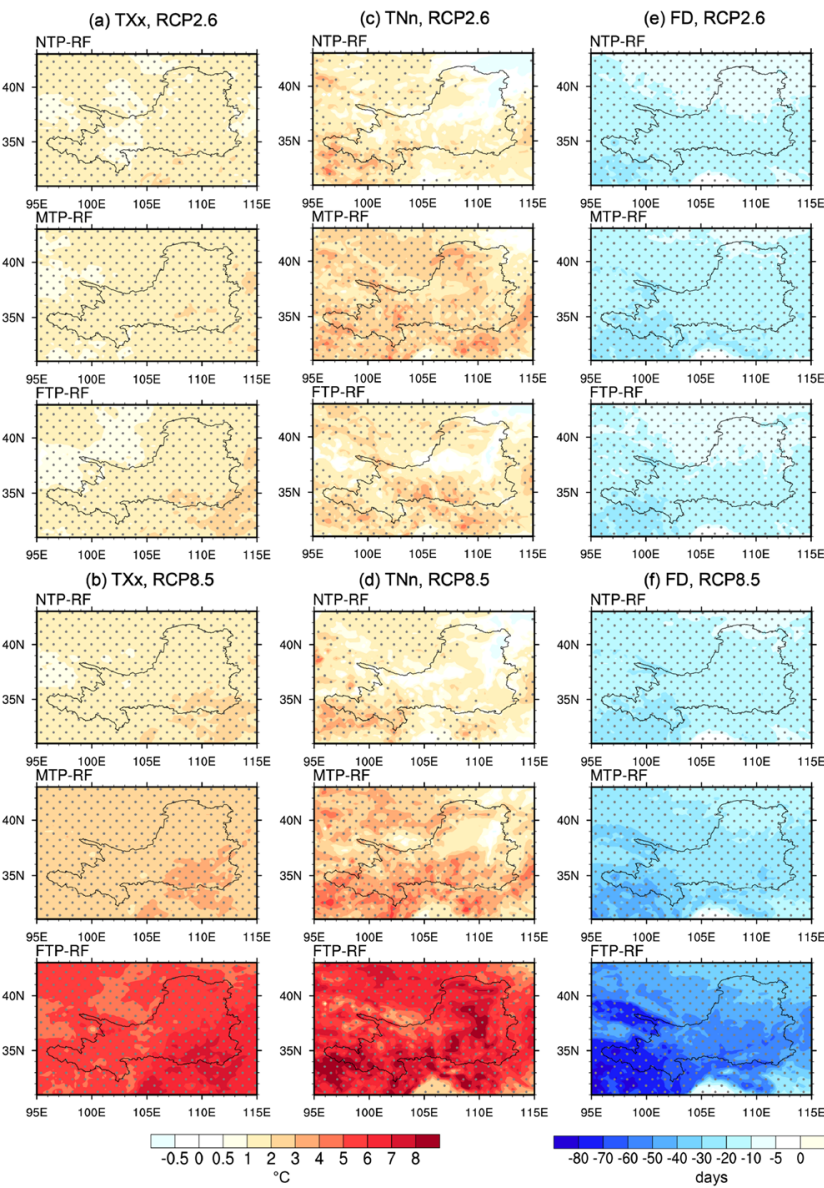

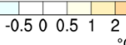
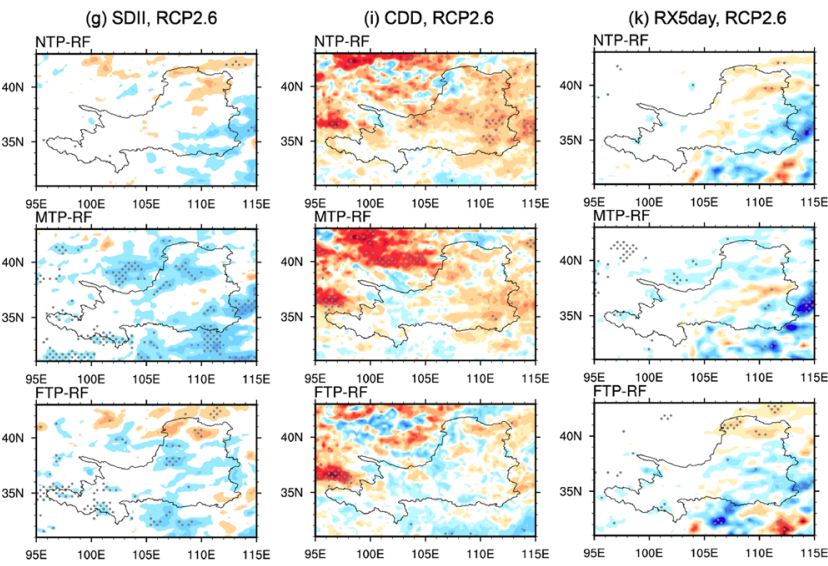

(h) SDII, RCP8.5

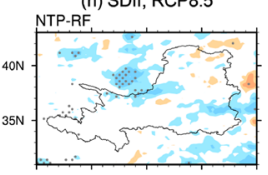

(j) CDD, RCP8.5
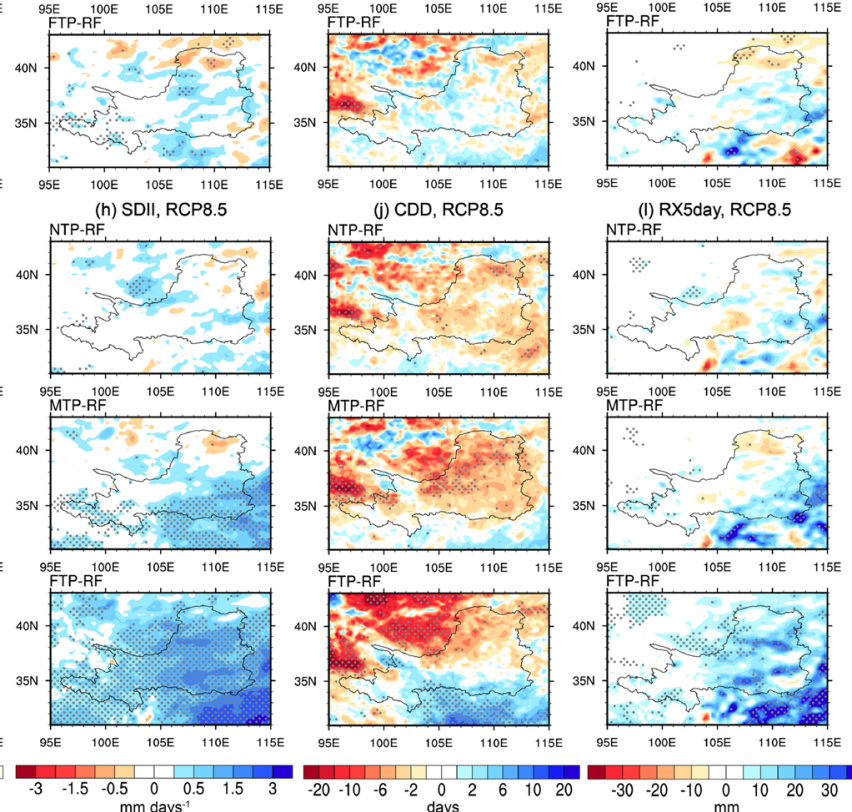

Fig. 11 Projected changes in TXx, TNn, FD, SDII, CDD, and RX5day for the NTP (2021-2040), MTP (2041-2060), and FTP (2081-2100) relative to the RF (1986-2005) under RCP 2.6 (upper) and under 8.5 (lower) according to the ensemble means of the three

\subsubsection{Elevation dependency of changes in mean climate and extreme events}

In this section, the relationships between elevation and changes in seasonal mean temperature and extreme temperature indices are investigated for the three future periods, relative to the RF. The increases in mean temperature have a clear elevation dependency in all seasons except in JJA (Fig. 12), indicating that the projected increases in mean temperature are amplified with elevation. This is particularly true in DJF under RCP 8.5, with a linear trend of $0.6{ }^{\circ} \mathrm{C}$ $\mathrm{km}^{-1}$ for the FTP relative to the RF, followed by MAM. In JJA, the increase in mean temperature decreases slightly with elevation. In SON, there is no elevation dependency for the increase in mean temperature below approximately $2000 \mathrm{~m}$. When it comes to extreme temperature, the increase in TXx decreases rapidly with the elevation at altitudes below around $2000 \mathrm{~m}$, and remains slightly decreasing at altitudes above $2000 \mathrm{~m}$ under RCP 2.6 (Fig. 13). Under RCP

REMO simulations. The black dots in TXx, TNn, and FD indicate differences statistically significant at the $95 \%$ confidence level, and black dots in SDII, CDD, and RX5day indicate differences statistically significant at the $90 \%$ confidence level

8.5, the increase of TXX deceases with elevation, at a rate of $0.3{ }^{\circ} \mathrm{C} \mathrm{km}^{-1}$ for the FTP. The elevation dependency of the increase in TNn is clear for the NTP, and reaches a minimum for the FTP under RCP 8.5. As elevation increases, the decline in FD increases significantly. Under RCP 2.6, the elevation dependency of the FD decrease is similar in all three future periods. The elevation dependency of the decrease in FD is stronger under RCP 8.5 than under RCP 2.6, and strengthens as integration time increase. The linear trend in FD decreases with elevation reaches 7 days $\mathrm{km}^{-1}$ for the FTP under RCP 8.5.

\subsection{Possible mechanisms influencing future climate change}

\subsubsection{Changes in surface snow amount}

Temperature increases are greater at higher altitudes, which is a phenomenon known as elevation-dependent warming 

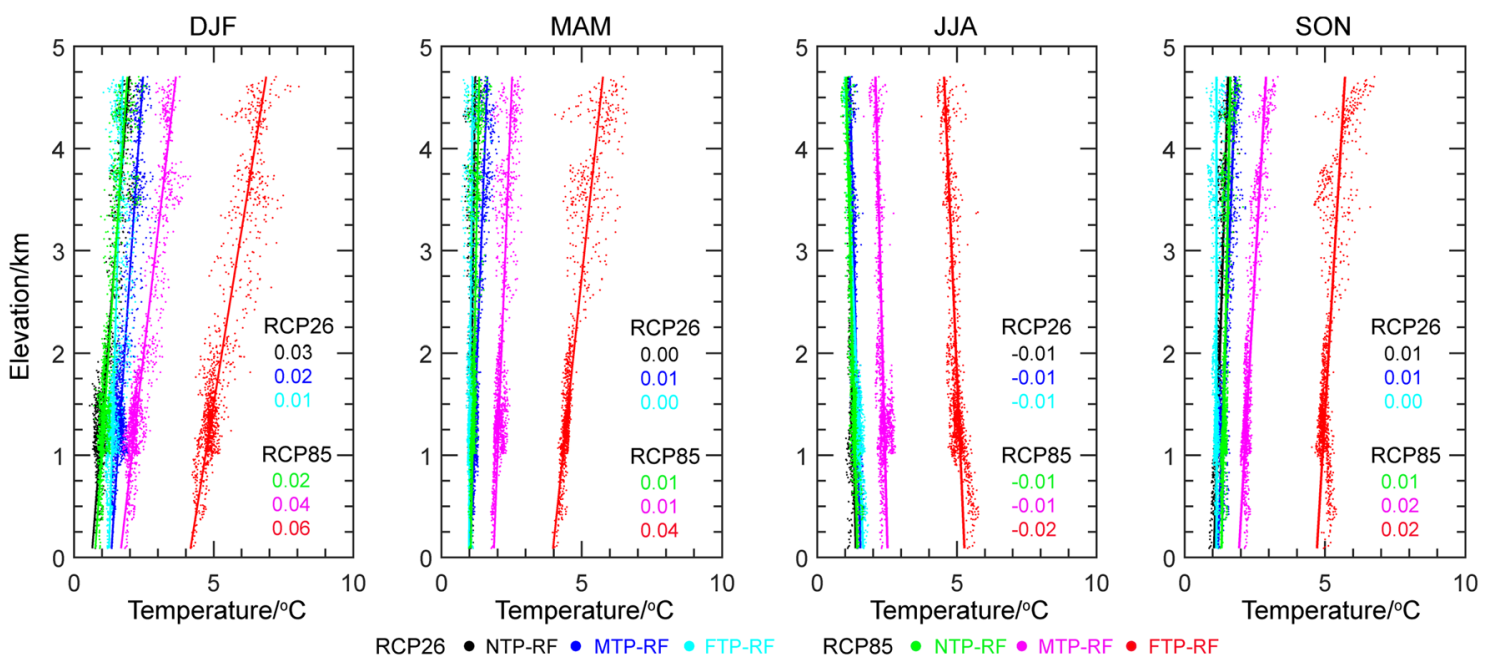

Fig. 12 Scatter plot between seasonal mean temperature change and elevation in the YRB. The gradient of the linear trend $\left({ }^{\circ} \mathrm{C} 100 \mathrm{~m}^{-1}\right)$ is marked on each panel. All trends are significant at the confidence level of 95\% according to a two-tailed Student's $t$ test (except for a trend of 0 )

Fig. 13 As Fig. 12, but for temperature-related extreme indices, TXX $\left({ }^{\circ} \mathrm{C} 100 \mathrm{~m}^{-1}\right)$, TNn $\left({ }^{\circ} \mathrm{C} 100 \mathrm{~m}^{-1}\right)$, and FD (days $100 \mathrm{~m}^{-1}$ ). The gradients for the linear trends are shown in each panel and all trends are significant at the $95 \%$ confidence level
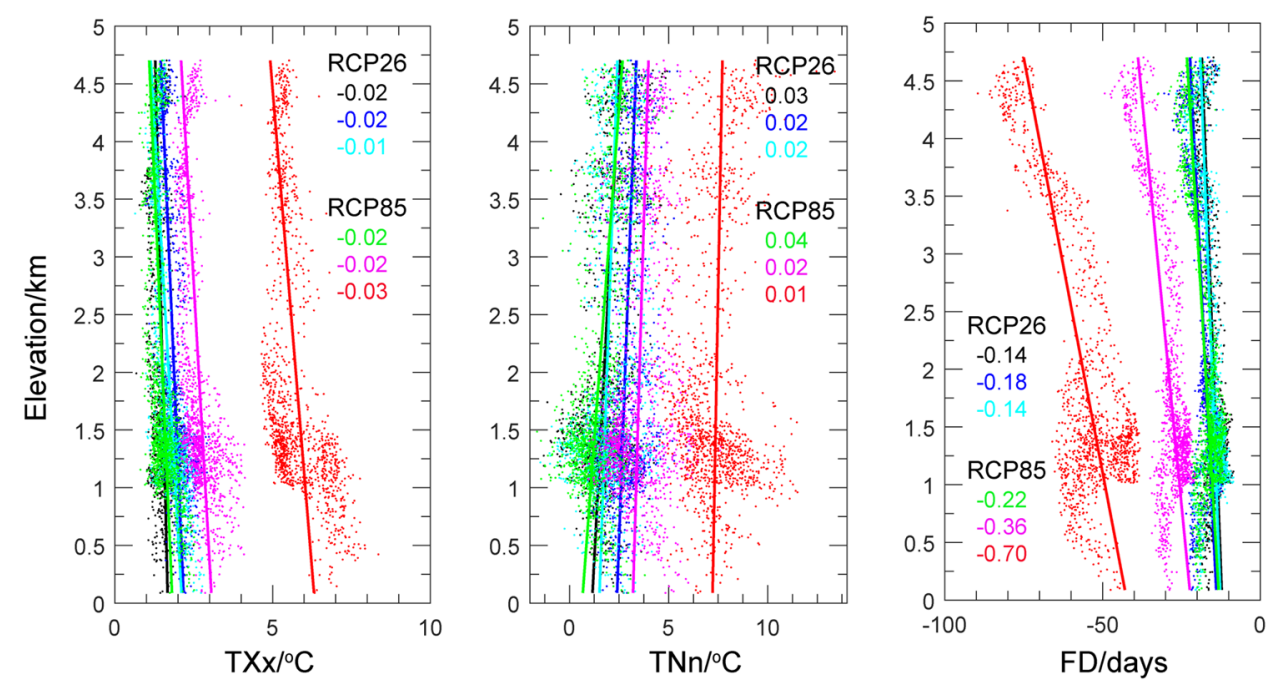

RCP85 • NTP-RF • MTP-RF • FTP-RF
(Pepin et al. 2015). As shown in Fig. 14, surface snow amounts in areas at high elevation, including the source region, reduces as temperatures increase, resulting in a decreased surface albedo, and so allowing more solar radiation to heat the surface. This positive albedo feedback leads to more pronounced temperature rises and to a decline in FD in the source region, especially in DJF and MAM, when most of the higher elevation regions of the YRB, including glacier and snow-covered areas, receive solid precipitation (Yang et al. 2019). The projected warming in DJF and MAM is likely to drive changes to the fractional distribution of solid and total precipitation (Leung et al. 2004; Pavelsky et al. 2012; Dimri et al. 2018). In a warmer climate, a greater proportion of precipitation is speculated to fall as rain, rather than snow, and so the projected temperature and precipitation increases in the YRB will drive a decrease in snow accumulation. The change to the proportion of precipitation that falls as snow under a warming climate warrants further study.

\subsubsection{Changes to large scale atmospheric circulation}

In the section, we assess simulated large-scale atmospheric circulation in the ENS to investigate drivers for the projected changes. We compare $500 \mathrm{hPa}$ geopotential height field, winds, specific humidity and moisture flux convergence at $850 \mathrm{hPa}$ under the two RCP scenarios over the much larger CORDEX East Asia domain. Given precipitation varies between the three future periods that we have 
(a) RCP26, NTP - RF

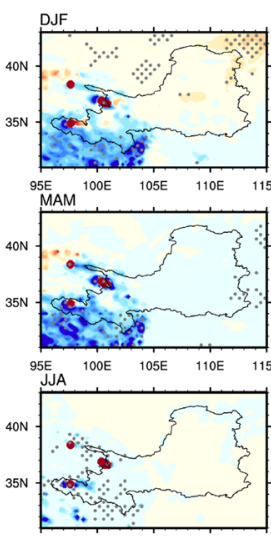

(b) RCP26, MTP - RF
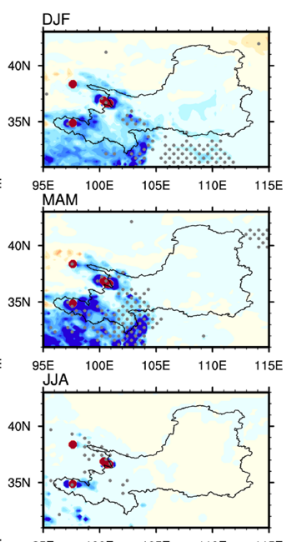

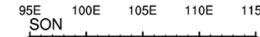
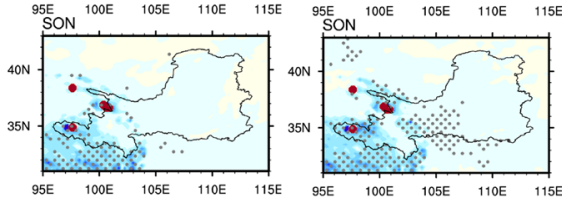

(c) RCP26, FTP - RF
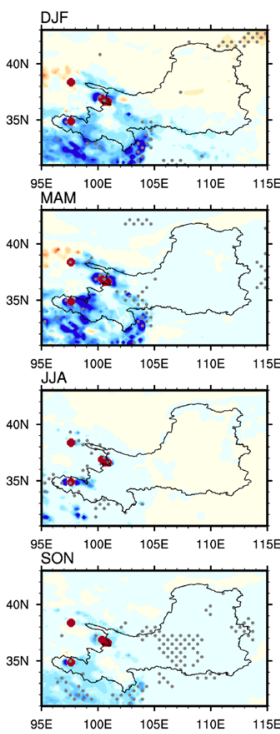

(d) RCP85, NTP-RF
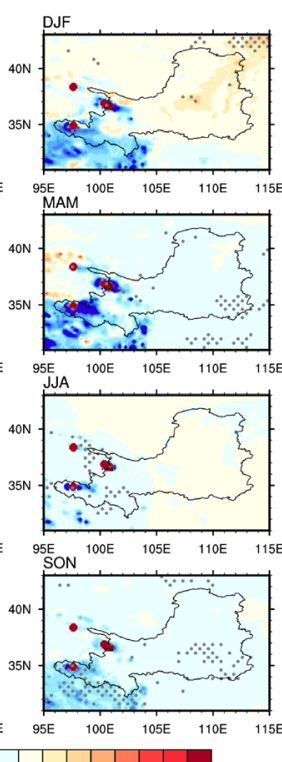

(e) RCP85, MTP-RF

(f) RCP85, FTP-RF
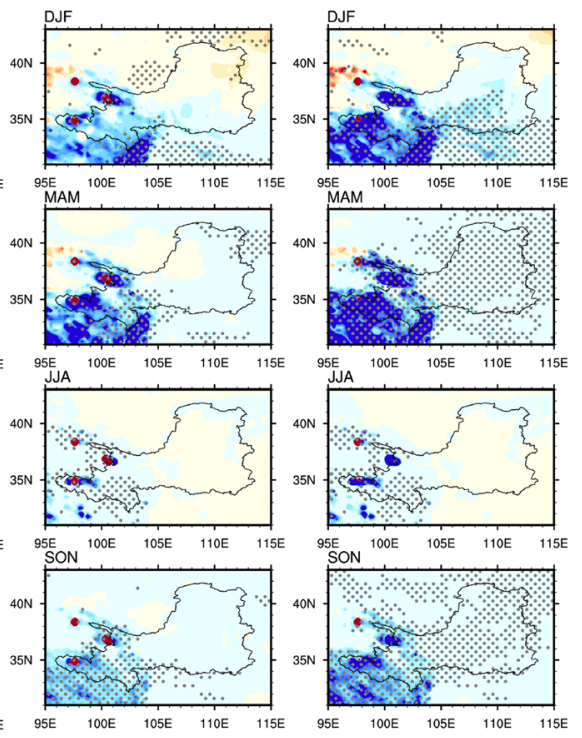

Fig. 14 Projected changes in surface snow amount for the NTP (2021-2040), MTP (2041-2060), and FTP (2081-2100), relative to the RF (1986-2005) under RCP 2.6 and under RCP 8.5 according to

looked at, we focus here on large-scale changes for the FTP, relative to the RF.

The so-called East Asian Trough (EAT), a feature of the $500 \mathrm{hPa}$ geopotential height (GPH), occurs to the east of the Eurasian continent and modulates the climate over east Asia during the cold season. The trough line is most commonly located around $140^{\circ} \mathrm{E}$ during winter, and is aligned along a northwest-southeast axis north of approximately $50^{\circ} \mathrm{N}$, and along a northeast-southwest axis south of $50^{\circ}$ $\mathrm{N}$ (Wang et al. 2009). West of the EAT, large-scale sinking motion gives rise to strong radiative cooling and contributes to the development of the Siberia High, which drives cold air movement during the boreal winter (Chen et al. 2005; Song et al. 2016). The ENS is able to reproduce the main spatial distribution of GPH shown in ERA-Interim data for the RF (Fig. 15), although the ENS representation includes some underestimation of value and gradient in GPH, especially over the Pacific Ocean (around $40 \mathrm{~m}$ ). The changes of GPH at $500 \mathrm{hPa}$ manifest that the atmosphere is projected to warm and the GPH to increase over the entire domain, and a substantial increase would appear over high latitude areas in DJF, especially for the FTP under RCP 8.5. Specifically, a strong increase in the GPH appears over Northeast Asia, where the EAT exists during the RF, meaning a weakening and northeastward shift of the EAT. This would make cold waves relatively less intense, which is consistent with the result of an earlier study that used CMIP5 GCMs (Xu et al. 2016). The simulated weakening of EAT is likely to partially account for the ensemble mean of the three REMO simulations. The black dots indicate differences statistically significant at the $95 \%$ confidence level

the projected increases in air temperature and $\mathrm{TNn}$, and for the projected decrease in wintertime FD.

Precipitation extremes are widely recognized to increase proportionately to mean atmospheric water vapor content (O'Gorman and Schneider 2009). Specific humidity is projected to increase in response to higher temperatures, with particularly large increases in northern China and Mongolia during DJF and SON under RCP 8.5 (Fig. 16). The YRB would experience a continuous growth in specific humidity, which is relevant to the wider picture of climate change, however greater increases are seen in DJF and in the RCP 8.5 simulation.

Westerly airflow dominates the mid-to high latitudes and the Asian monsoon dominates the circulation system over the Indian and Pacific oceans during the warm season. The ENS and the individual model simulations project much stronger southeasterly winds for the YRB in DJF under RCP 2.6 and RCP 8.5 than were present in the RF (Fig. S11). The anomalous southeasterlies indicate a weaker winter monsoon and enhanced water vapor transport into the YRB. The convergence of warm and moist airflows with the prevailing cold northwesterly airflows is more likely to trigger precipitation and reduce CDD. In MAM, the westerlies would be intensified, facilitating increased moisture transport into the YRB, which would contribute to an increase in precipitation.

A larger increase in $500 \mathrm{hPa}$ GPH occurs over southwestern China and the southern Tibetan Plateau than the Indian Ocean in JJA (Fig. 15). The increased meridional gradient at $500 \mathrm{hPa}$ strengthens the Indian monsoon circulation in the future, as 

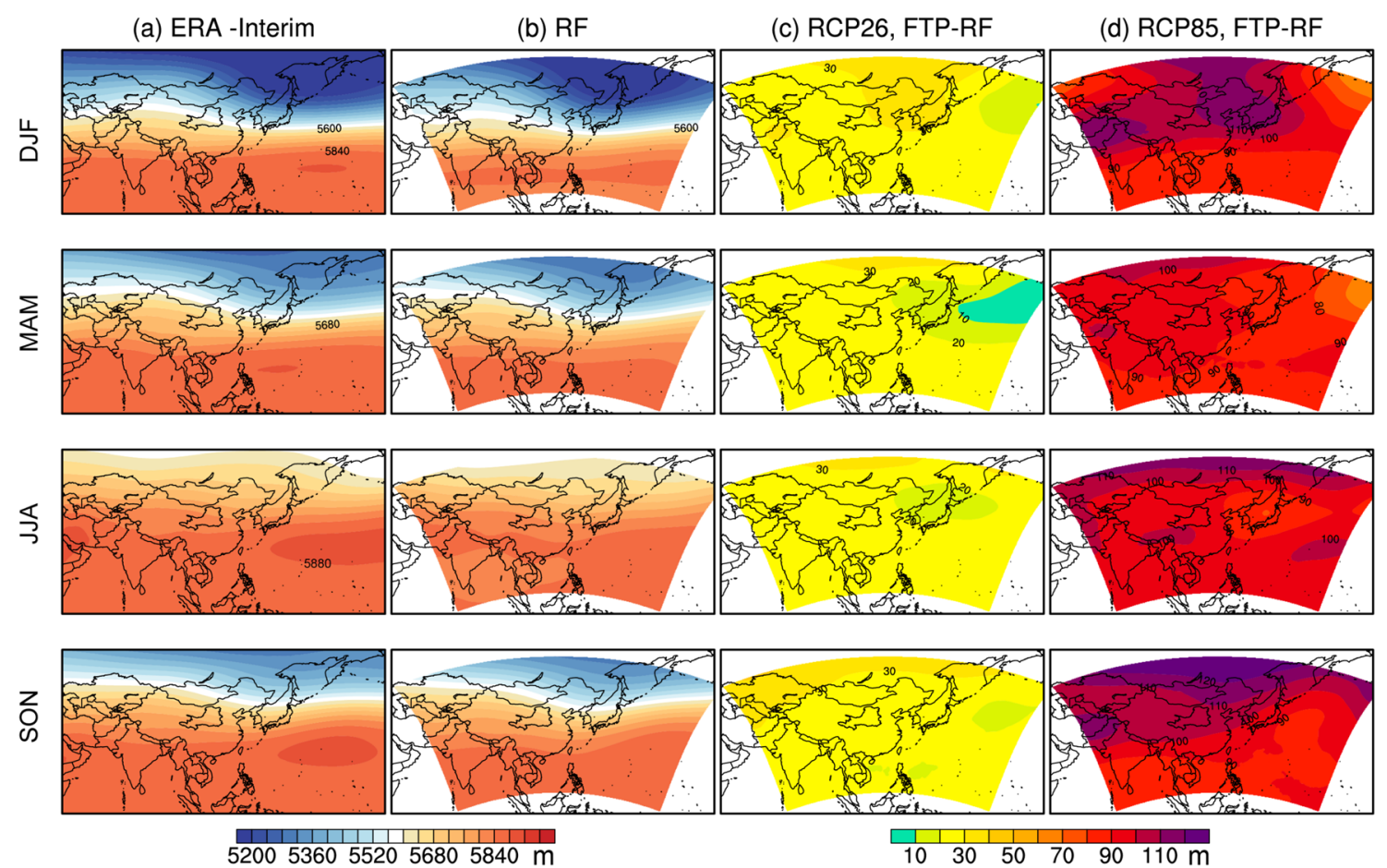

Fig. 15 Spatial distributions of seasonal geopotential height at $500 \mathrm{hPa}$ for the RF (1986-2005) in a ERA-Interim and b ENS, and for the FTP (2081-2100), relative to RF, c under RCP 2.6 and

indicated by $850 \mathrm{hPa}$ winds in Fig. 16. However, moisture flux from the Bay of Bengal is weakened by coast mountain ranges and inland mountains and the increased circulation, analogous to the anticyclone, to the southeast of the YRB, is not favorable for moisture flux convergence (Fig. 16d), and actually results in decreased precipitation in the southern YRB. The three models diverge in their representation of the strength of the monsoon circulation under both emissions scenarios (Figs. S10, S11), leading to large uncertainties for simulated JJA precipitation. For example, the Indian monsoon is strongest in the Had_R simulations, which simulate the largest increases in mean and extreme precipitation. In contrast, the monsoon circulation in the MPI_R simulations is weak and generates only minor changes in moisture. This combines with an anomalous anticyclonic circulation over the eastern YRB to significantly decrease precipitation in the RCP 8.5 simulations. In SON, the anomalous northeasterlies encounter with the southerlies during the monsoon retreat period, contributing to the increased precipitation in the northeastern YRB under RCP 8.5.

\section{Discussion}

Use of multi-RCM ensembles is an important way to provide more reliable projections of climate. However, only limited CORDEX RCM simulations for the East Asia domain are d under RCP 8.5 , respectively. The results for the RF and FTP are based on the ensemble means of the three REMO model simulations

currently available. We thus discuss the projection results in this study in the light of simulations from other RCMs and CMIP5 GCMs ensemble simulations that cover the YRB. We focus on mean and extreme precipitation because of the high uncertainty associated with projections for precipitation. Simulations form RegCM4, driven by Geophysical Fluid Dynamics Laboratory (GFDL) GCM, project a persistent increase in annual precipitation between 2070 and 2099 under RCP 4.5 and RCP 8.5 (Lu et al. 2019). The decrease in CDD projected in our study concurs with results from RegCM4 simulations driven by HadGEM2-ES, which project that the consecutive dry days will reduce in North China under RCP 8.5 (Shi et al. 2018). Multi-RCM ensembles under the A1B scenario suggest the winter CDD will decline during the MTP (Niu et al. 2018). Four groups of RCM experiments (RegCM4 and WRF, separately driven by EC-Earth and IPSL-CM5A) project significant increases in RX5day for the MTP under RCP 8.5 (Hui et al. 2018). The RCM PRECIS, forced by HadGEM2-ES, projects positive trends in SDII from the 2050s to the 2080s under RCP 8.5 (Zhu et al. 2018). Projections simulated using RegCM4 show a strong increase in RX5day for the middle reaches of the YRB in the 2080s (Lu et al. 2019).

Results from an 11-number ensemble of CMIP5 GCMs show significant precipitation increases over the YRB for the MTP and FTP under RCP 2.6 and RCP 8.5 (Xu and 
(a) RF
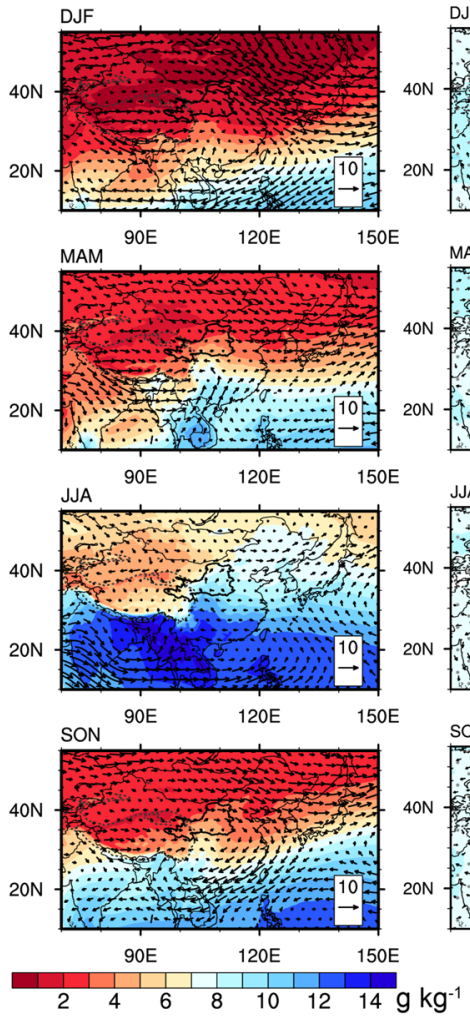

(b) RCP26, FTP-RF
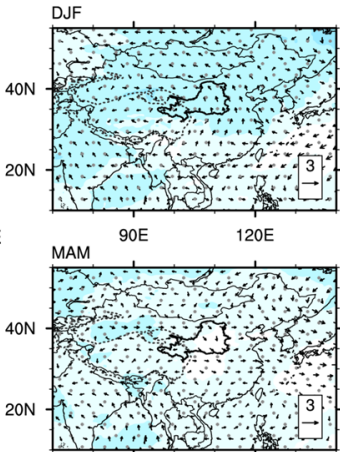

TOE $\quad 120 \mathrm{E}$

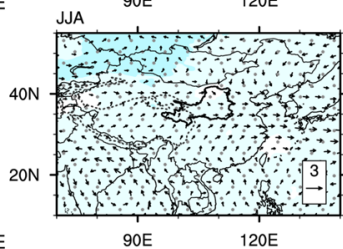

(c) RCP85, FTP-RF
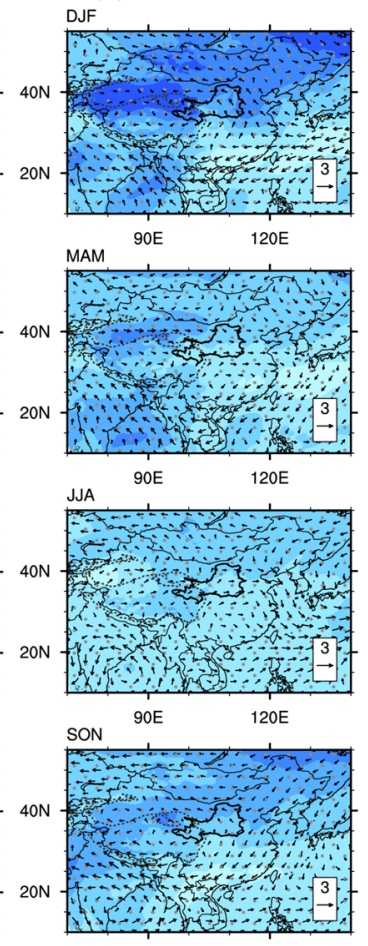

$90 \mathrm{E}$

$120 \mathrm{E}$
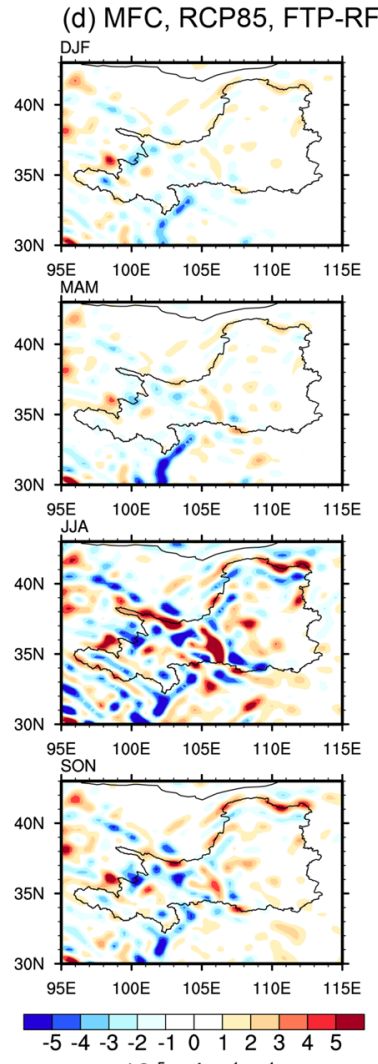

$10^{-5} \mathrm{~g} \mathrm{~kg}^{-1} \mathrm{~s}^{-1}$

Fig. 16 Spatial distribution of wind $\left(\mathrm{m} \mathrm{s}^{-1}\right)$ and specific humidity at $850 \mathrm{hPa}$ for the RF (1986-2005) and changes to these for the FTP (2081-2100), relative to the RF, calculated from the ensemble means of the three REMO simulations under RCP 2.6 and under RCP 8.5. d Shows the projected changes in horizontal moisture flux convergence

Xu 2012). The multi-model ensemble simulations suggest that precipitation in the YRB will become more abundant because precipitation increase will exceed $10 \%$ in the northern YRB but be less than 10\% for the rest of the area, the increase in SDII is projected to exceed $10 \%$ for the MTP (at a high confidence level) under RCP 4.5, CDD is projected to decrease by less than $10 \%$ (at a low confidence level) (Li et al. 2016). Under RCP 8.5, total precipitation and RX5day are projected to increase significantly, while there is no significant change projected for CDD (Zhou et al. 2014). Projections of future climate from GCMs are generally more spatially homogeneous, whereas regional differences are apparent in RCMs. Overall, the changes projected for extreme precipitation indices suggest that in the future the YRB will experience fewer dry days (at a low confidence level) and SDII and RX5day will increase significantly, although the absolute increase in mean precipitation varies between the projections from RCMs and GCMs.

This study presents the results of one RCM driven, separately, by three different GCMs. Although some comparisons are made with other RCM simulations, these comparisons
(MFC) at $850 \mathrm{hPa}$ for the FTP, relative to the RF, under RCP 8.5. The dashed lines in a-c are contours representing $3000 \mathrm{~m}$ surface elevation. The gray dots indicate where changes in specific humidity $\mathbf{b}, \mathbf{c}$ are significant at the $95 \%$ confidence level

should be treated with caution as the different simulations correspond to different driving GCMs, different emissions scenarios and different model configurations. Moreover, this study adopts 20 -year time slice to investigate the future climate changes, following the current studies of climate projection and allowing other subsequent studies to compare the results. However, this aspect is likely to be subject to the impact of internal variability, especially for precipitation (Dai and Bloecker 2019). An alternative approach to narrow the effect is recommended to use longer time slice (Hawkins and Sutton 2016), such as the climatological standard normals ( 30 years). Besides, to enhance the reliability of future climate change projections, it is necessary to conduct large simulation ensembles using different RCMs forced by different GCMs, and to consider simulations from the next generation of GCMs, CMIP6 GCMs (Jiang et al. 2020), because of several improvements in terms of spatial resolution, model performance, and model physics over CMIP5 models.

The current study area, the YRB, is far smaller than the CORDEX East Asian domain. Large-scale horizontal circulation changes caused by rising GHG concentrations 
comprise the background for changes to climate in the YRB, especially for precipitation changes. Previous climate projection studies have shown that opposing changes to GPH may occur over land and ocean, leading to changes in atmospheric circulations and moisture transport over the mainland of China, and driving precipitation changes (Gao et al. 2011; Niu et al. 2018). In addition, land-atmosphere feedbacks, such as soil moisture-evapotranspiration-precipitation, may be an important influencing factor (Liu et al. 2014). Local and vertical convection may also play a role since the REMO simulations show small-scale changes to moisture flux and convergence, driven by the fine-scale topographic forcing (Fig. 16d) and both precipitation and evaporation are projected to intensify (Huntington 2006; O'Gorman and Schneider 2009). Radiation forcing, caused by the spatially non-uniform increases in GHGs, is the primary driver for temperature increases in the source region, however local surface feedback like the snow albedo effect, are likely to amplify the warming at high elevations. Temperature increases during the cold season may also be partially driven by enhanced downward longwave radiation caused by increased surface water vapor, as suggested by Rangwala et al. (2013). The sensitivity of longwave radiation to changes in surface water vapor increases with elevation (Ruckstuhl et al. 2007) and so increased moisture levels are likely to have a greater impact on downward longwave radiation at higher elevations, leading to greater increases in surface temperature in the high elevation source region.

The effect of lakes on climate is noted here. Large lakes play a significant role in regional climate because they can regulate the distribution of precipitation and initiate, and sometimes markedly increase, snow cover through lakeeffect snow (Dai et al. 2020). Figures 4 and 14 show some anomalies in precipitation and snow cover amount around the Qinghai Lake and Ngoring and Gyaring lakes in the source region, which are likely to be attributable to effects driven by the lakes. More investigation is needed to better understand the climatic significance of lakes. Convectionpermitting models with a horizontal grid spacing of less than $4 \mathrm{~km}$ can explicitly resolve convection and have been shown to offer improved representations of temperature and precipitation (Prein et al. 2015). These are therefore very promising tools for high-resolution modeling studies, such as investigations into the role of lakes in regional climate, and can be used to reduce uncertainties for future climate projections over the study area.

\section{Conclusions}

In this study, we have evaluated REMO model simulations driven by the three GCMs (HadGEM2-ES, MPI-ESMLR, and NCC-NorESM1-M) through comparison with observations for the historical period, and have assessed future projected changes in both mean and extreme conditions for the upper and middle reaches of the YRB under RCP 2.6 and RCP 8.5. REMO can well simulate the spatial distributions for the mean values and extremes of temperature and precipitation. Simulations of the mean and extreme temperature are more reliable than simulations of the mean and extreme precipitation, although there remain biases such as some underestimated temperature and overestimated precipitation. The downscaled simulations show clear advantages over the GCM simulations in reproducing mean (temperature and precipitation) and extreme conditions (TXx, FD, SDII, and RX5day), by either reduced biases or more realistic representation of spatial variations.

Mean temperature is projected to increase, especially for the YR source region and in DJF. Future temperature is likely to increase initially up to a peak, after which it will decrease slightly under RCP 2.6. Under RCP 8.5, warming is projected to accelerate in the future, resulting in increases of $5.6{ }^{\circ} \mathrm{C}$ in DJF, $5.4{ }^{\circ} \mathrm{C}$ in SON, $5.3^{\circ} \mathrm{C}$ in JJA, and $4.9^{\circ} \mathrm{C}$ in MAM in the FTP, relative to the RF (1986-2005). Monthly mean temperature is projected to increase as emissions increase and the strongest simulated increase is in DJF under RCP 8.5.

Mean precipitation is projected to increase in DJF and could reach $34 \%$ by the end of twenty first century under RCP 8.5, although the absolute amount of winter precipitation remains relatively low. Precipitation in MAM is projected to increases under the both RCP scenarios, while projections for precipitation changes in JJA and SON are spatially variable. Under RCP 8.5 , a slightly decrease for precipitation is projected in JJA, while there is an increase in SON. The annual cycle will likely decrease, because TNn is projected to increase more than TXx and precipitation is projected to increase in dry season but not in wet season. REMO projects a strong increase in interannual variability for mean precipitation over most of the YRB in response to warming and the two emissions scenarios have a noticeable impact on precipitation during winter and spring months.

Temperature extremes, indicated by indices such as TXx and $\mathrm{TNn}$, are projected to increase and FD is projected to decline. Changes to TNn are projected to be more drastic than changes to TXx under RCP 8.5. The model predicts a generally enhanced SDII, most notably in the middle reaches. CDD is predicted to steadily decrease, except for the FTP under RCP 2.6. RX5day is projected to generally increase slightly under RCP 2.6, but will increase in the middle reaches, by $12 \%$ on average, by the end of twenty first century under RCP 8.5.

GHG concentrations with low spatial variability are primarily responsible for widespread future warming, and the albedo effect caused by the depletion of snow cover is likely to amplify warming at high elevations, such as in the source 
region. The relationship between elevation and the extent of the warming is clearer for $\mathrm{FD}$, and for mean temperature in DJF and MAM.

Under RCP 8.5, considerable rises in GPH for high-latitude areas in DJF suggest that a weakening and poleward shift of EAT contributes to the increase in TNn and to the decrease in FD. The possible drivers for future changes to precipitation are specific humidity and atmospheric circulation, with the former having a stronger effect. Climate warming increases the volume of moisture that can be stored in the atmosphere over the YRB, particularly in DJF under RCP 8.5. Under the high emissions scenario, anomalous winds and increased minor circulations significantly influence on both mean and extreme precipitation.

Temperature increases in the source region of the YR will aggravate cryosphere degradation and change the associated runoff. Cryospheric features such as glaciers and frozen ground are likely to shrink persistently under both future emissions scenarios (Yang et al. 2019). The simulated increases in precipitation events and precipitation intensity in the YRB suggest that the area may experience a greater flood risk in the future. The storage function of the solid water reservoir in the source region will reduce as the snow volume decreases, and the interannual variability of precipitation is expected to increase, particularly under RCP 8.5, thereby exacerbating the flood risk for the mid-and lower reaches of the YRB. The projections of future climate presented in this study will be helpful to policy-making for climate mitigation and adaptation.

Acknowledgements This research was supported by the Strategic Priority Research Program of the Chinese Academy of Sciences (CAS) (XDA19070204), the National Key Research and Development Program of China (2019YFC0507401), the Innovation Research Group of NSFC (41721091), the Strategic Priority Research Program of the CAS (XDA20100102), the National Natural Science Foundation of China (41771068), the Youth Innovation Promotion Association CAS (2018460), and the Program of China Scholarship Council (201804910129, 201908625013). We acknowledge the CORDEX and GERICS for providing the REMO downscaling data (https://esg-dn1. nsc.liu.se/search/cordex/). The computations were enabled by resources provided by the Swedish National Infrastructure for Computing (SNIC) at [SNIC CENTRE] partially funded by the Swedish Research Council through Grant Agreement no. 2019-32-6.

Funding Open Access funding provided by University of Gothenburg.

Open Access This article is licensed under a Creative Commons Attribution 4.0 International License, which permits use, sharing, adaptation, distribution and reproduction in any medium or format, as long as you give appropriate credit to the original author(s) and the source, provide a link to the Creative Commons licence, and indicate if changes were made. The images or other third party material in this article are included in the article's Creative Commons licence, unless indicated otherwise in a credit line to the material. If material is not included in the article's Creative Commons licence and your intended use is not permitted by statutory regulation or exceeds the permitted use, you will need to obtain permission directly from the copyright holder. To view a copy of this licence, visit http://creativecommons.org/licenses/by/4.0/.

\section{References}

Ahmed A, Nawaz R, Woulds C, Drake F (2020) Influence of hydroclimatic factors on future coastal land susceptibility to erosion in Bangladesh: a geospatial modelling approach. J Geovis Spat Anal 4(1):6. https://doi.org/10.1007/s41651-020-00050-x

Arnell NW, Lowe JA, Challinor AJ, Osborn TJ (2019) Global and regional impacts of climate change at different levels of global temperature increase. Clim Change 155(3):377-391. https://doi. org/10.1007/s10584-019-02464-z

Bentsen M, Bethke I, Debernard J, Iversen T, Kirkevåg A, Seland Ø, Drange H, Roelandt C, Seierstad I, Hoose C (2013) The Norwegian earth system model, NorESM1-M-Part 1: description and basic evaluation of the physical climate. Geosci Model Dev 6(3):687-720. https://doi.org/10.5194/gmd-6-687-2013

Chen W, Yang S, Huang R-H (2005) Relationship between stationary planetary wave activity and the East Asian winter monsoon. J Geophys Res Atmos 110(D14):D14110. https://doi. org/10.1029/2004jd005669

Chou C, Chiang JC, Lan C-W, Chung C-H, Liao Y-C, Lee C-J (2013) Increase in the range between wet and dry season precipitation. Nat Geosci 6(4):263-267. https://doi.org/10.1038/NGEO1744

Collins W, Bellouin N, Doutriaux-Boucher M, Gedney N, Halloran P, Hinton T, Hughes J, Jones C, Joshi M, Liddicoat S (2011) Development and evaluation of an Earth-System model-HadGEM2. Geosci Model Dev 4(4):1051-1075. https://doi.org/10.5194/ gmdd-4-997-2011

Collins M, Knutti R, Arblaster J, Dufresne J-L, Fichefet T, Friedlingstein P, Gao X, Gutowski WJ, Johns T, Krinner G (2013) Longterm climate change: projections, commitments and irreversibility. In: Climate Change 2013-The Physical Science Basis: Contribution of Working Group I to the Fifth Assessment Report of the Intergovernmental Panel on Climate Change. Cambridge University Press, pp 1029-1136

Cong Z, Zhao J, Yang D, Ni G (2010) Understanding the hydrological trends of river basins in China. J Hydrol 388(3):350-356. https:// doi.org/10.1016/j.jhydrol.2010.05.013

Cubasch U, Wuebbles D, Chen D, Facchini M, Frame D, Mahowald N, Winther J (2013) Introduction. In: Stocker TF, Qin D, Plattner GK, Tignor M, Allen SK, Boschung J, Nauels A, Xia Y, Bex V, Midgley PM (eds) Climate change 2013: the physical science basis. Contribution of Working Group I to the Fifth Assessment Report of the Intergovernmental Panel on Climate Change. Cambridge University Press, Cambridge, p 1535

Dai A, Bloecker CE (2019) Impacts of internal variability on temperature and precipitation trends in large ensemble simulations by two climate models. Clim Dyn 52(1):289-306. https://doi. org/10.1007/s00382-018-4132-4

Dai Y, Wang L, Yao T, Li X, Zhu L, Zhang X (2018) Observed and simulated lake effect precipitation over the Tibetan Plateau: an initial study at Nam Co Lake. J Geophys Res Atmos 123(13):67466759. https://doi.org/10.1029/2018jd028330

Dai Y, Chen D, Yao T, Wang L (2020) Large lakes over the Tibetan Plateau may boost snow downwind: implications for snow disaster. Sci Bull. https://doi.org/10.1016/j.scib.2020.06.012

Dee DP, Uppala SM, Simmons A, Berrisford P, Poli P, Kobayashi S, Andrae U, Balmaseda M, Balsamo G, Bauer DP (2011) The ERA-Interim reanalysis: configuration and performance of the data assimilation system. Q J R Meteorol Soc 137(656):553-597 
Dimri A, Kumar D, Choudhary A, Maharana P (2018) Future changes over the Himalayas: mean temperature. Glob Planet Change 162:235-251. https://doi.org/10.1016/j.gloplacha.2018.01.014

Donat MG, Lowry AL, Alexander LV, O'Gorman PA, Maher N (2016) More extreme precipitation in the world's dry and wet regions. Nat Clim Change 6(5):508-513. https://doi.org/10.1038/nclim ate2941

Gao Y, Chen D (2017) Modeling of regional climate over the Tibetan Plateau. Oxford research encyclopedia of climate science. Oxford University Press, Oxford

Gao X, Shi Y, Giorgi F (2011) A high resolution simulation of climate change over China. Sci China Earth Sci 54(3):462-472. https:// doi.org/10.1007/s11430-010-4035-7

Gao X, Shi Y, Giorgi F (2016) Comparison of convective parameterizations in RegCM4 experiments over China with CLM as the land surface model. Atmos Ocean Sci Lett 9(4):246-254. https://doi. org/10.1080/16742834.2016.1172938

Ge J, Pitman AJ, Guo W, Wang S, Fu C (2019) Do uncertainties in the reconstruction of land cover affect the simulation of air temperature and rainfall in the CORDEX Region of East Asia? J Geophys Res Atmos 124(7):3647-3670. https://doi.org/10.1029/2018j d029945

Ghosh KG (2018) Analysis of rainfall trends and its spatial patterns during the last century over the Gangetic West Bengal, Eastern India. J Geovis Spat Anal 2(2):15. https://doi.org/10.1007/s4165 $1-018-0022-x$

Giorgi F (2019) Thirty years of regional climate modeling: where are we and where are we going next? J Geophys Res Atmos 124(11):5696-5723. https://doi.org/10.1029/2018JD030094

Gou X, Deng Y, Chen F, Yang M, Fang K, Gao L, Yang T, Zhang $F$ (2010) Tree ring based streamflow reconstruction for the Upper Yellow River over the past 1234 years. Chin Sci Bull 55(36):4179-4186. https://doi.org/10.1007/s11434-010-4215-Z

Greve P, Orlowsky B, Mueller B, Sheffield J, Reichstein M, Seneviratne SI (2014) Global assessment of trends in wetting and drying over land. Nat Geosci 7(10):716-721. https://doi.org/10.1038/ngeo2 247

Hagemann S (2002) An improved land surface parameter dataset for global and regional climate models. Max-Planck-Institut für Meteorol. http://hdl.handle.net/11858/00-001M-0000-002B-539B-6

Hagemann S, Botzet M, Dümenil L, Machenhauer B (1999) Derivation of global GCM boundary conditions from $1 \mathrm{~km}$ land use satellite data. MPI Report No. 289

Hawkins E, Sutton R (2016) Connecting climate model projections of global temperature change with the real world. Bull Am Meteorol Soc 97(6):963-980. https://doi.org/10.1175/bams-d-14-00154.1

Hu Z, Chen X, Chen D, Li J, Wang S, Zhou Q, Yin G, Guo M (2019) "Dry gets drier, wet gets wetter": a case study over the arid regions of central Asia. Int J Climatol 39(2):1072-1091. https://doi. org/10.1002/joc. 5863

Hui P, Tang J, Wang S, Wu J, Kang Y (2014) Future climate projection under IPCC A1B scenario in the source region of Yellow River with complex topography using RegCM3. J Geophys Res Atmos 119(19):11205-211222. https://doi.org/10.1002/2014jd021992

Hui P, Tang J, Wang S, Niu X, Zong P, Dong X (2018) Climate change projections over China using regional climate models forced by two CMIP5 global models. Part II: projections of future climate. Int J Climatol 38(S1):e78-e94. https://doi.org/10.1002/joc.5409

Huntington TG (2006) Evidence for intensification of the global water cycle: review and synthesis. J Hydrol 319(1-4):83-95. https://doi. org/10.1016/j.jhydrol.2005.07.003

IPCC (2014) Climate Change 2013-the physical science basis: Working Group I Contribution to the Fifth Assessment Report of the Intergovernmental Panel on climate change. Cambridge University Press, Cambridge. https://doi.org/10.1017/CBO9781107 415324
IPCC (2019a) Summary for policymakers. In: IPCC special report on the ocean and cryosphere in a changing climate. https://www.ipcc. $\mathrm{ch} /$ srocc/chapter/summary-for-policymakers

IPCC (2019b) Climate change and land: an IPCC special report on climate change, desertification, land degradation, sustainable land management, food security, and greenhouse gas fluxes in terrestrial ecosystems. https://www.ipcc.ch/srccl/

Jacob D, Elizalde A, Haensler A, Hagemann S, Kumar P, Podzun R, Rechid D, Remedio AR, Saeed F, Sieck K (2012) Assessing the transferability of the regional climate model REMO to different coordinated regional climate downscaling experiment (CORDEX) regions. Atmosphere 3(1):181-199. https://doi.org/10.3390/atmos 3010181

Jiang D, Hu D, Tian Z, Lang X (2020) Differences between CMIP6 and CMIP5 models in simulating climate over China and the East Asian Monsoon. Adv Atmos Sci 37(10):1102-1118. https://doi. org/10.1007/s00376-020-2034-y

Jing W, Yao L, Zhao X, Zhang P, Liu Y, Xia X, Song J, Yang J, Li Y, Zhou C (2019) Understanding terrestrial water storage declining trends in the Yellow River Basin. J Geophys Res Atmos 124:12963-12984. https://doi.org/10.1029/2019JD031432

Jungclaus J, Fischer N, Haak H, Lohmann K, Marotzke J, Matei D, Mikolajewicz U, Notz D, Von Storch J (2013) Characteristics of the ocean simulations in the Max Planck Institute Ocean Model (MPIOM) the ocean component of the MPI-Earth system model. J Adv Model Earth Syst 5(2):422-446. https://doi. org/10.1002/jame.20023

Kiktev D, Sexton DMH, Alexander L, Folland CK (2003) Comparison of modeled and observed trends in indices of daily climate extremes. J Clim 16(22):3560-3571. https://doi. org/10.1175/1520-0442(2003)016<3560:comaot $>2.0$. co;2

Kong D, Miao C, Wu J, Duan Q (2016) Impact assessment of climate change and human activities on net runoff in the Yellow River Basin from 1951 to 2012. Ecol Eng 91:566-573. https://doi. org/10.1016/j.ecoleng.2016.02.023

Kumar P, Kotlarski S, Moseley C, Sieck K, Frey H, Stoffel M, Jacob D (2015) Response of Karakoram-Himalayan glaciers to climate variability and climatic change: a regional climate model assessment. Geophys Res Lett 42(6):1818-1825. https://doi. org/10.1002/2015g1063392

Leung LR, Qian Y, Bian X, Washington WM, Han J, Roads JO (2004) Mid-century ensemble regional climate change scenarios for the western United States. Clim Change 62(1):75-113. https ://doi.org/10.1023/b:clim.0000013692.50640.55

Li W, Jiang Z, Xu J, Li L (2016) Extreme precipitation indices over China in CMIP5 models. Part II: probabilistic projection. J Clim 29(24):8989-9004. https://doi.org/10.1175/jcli-d-16-0377.1

Liu C, Allan RP (2013) Observed and simulated precipitation responses in wet and dry regions 1850-2100. Environ Res Lett 8(3):034002. https://doi.org/10.1088/1748-9326/8/3/034002

Liu D, Wang G, Mei R, Yu Z, Yu M (2014) Impact of initial soil moisture anomalies on climate mean and extremes over Asia. J Geophys Res Atmos 119(2):529-545. https://doi. org/10.1002/2013JD020890

Lu C, Huang G, Wang X (2019) Projected changes in temperature, precipitation, and their extremes over China through the RegCM. Clim Dyn 53(9):5859-5880. https://doi.org/10.1007/ s00382-019-04899-7

Majewski D (1991) The Europa-Modell of the Deutscher Wetterdienst. ECMWF Proc Numer Methods Atmos Models Read 2:147-191

Meinshausen M, Smith SJ, Calvin K, Daniel JS, Kainuma MLT, Lamarque J-F, Matsumoto K, Montzka SA, Raper SCB, Riahi K, Thomson A, Velders GJM, van Vuuren DPP (2011) The RCP greenhouse gas concentrations and their extensions from 1765 
to 2300. Clim Change 109(1):213. https://doi.org/10.1007/s1058 4-011-0156-z

Niu X, Wang S, Tang J, Lee DK, Gutowski W, Dairaku K, McGregor J, Katzfey J, Gao X, Wu J (2018) Ensemble evaluation and projection of climate extremes in China using RMIP models. Int J Climatol 38(4):2039-2055. https://doi.org/10.1002/joc.5315

Niu X, Tang J, Wang S, Fu C, Chen D (2019) On the sensitivity of seasonal and diurnal precipitation to cumulus parameterization over CORDEX-EA-II. Clim Dyn 54:1-21. https://doi.org/10.1007/ s00382-019-05010-w

O'Gorman PA, Schneider T (2009) The physical basis for increases in precipitation extremes in simulations of 21st-century climate change. Proc Natl Acad Sci 106(35):14773-14777. https://doi. org/10.1073/pnas.0907610106

Pang G, Wang X, Chen D, Yang M, Liu L (2020) Evaluation of a climate simulation over the Yellow River Basin based on a regional climate model (REMO) within the CORDEX. Atmos Res (Under review)

Pavelsky TM, Sobolowski S, Kapnick SB, Barnes JB (2012) Changes in orographic precipitation patterns caused by a shift from snow to rain. Geophys Res Lett 39(18):L18706. https://doi. org/10.1029/2012g1052741

Pepin N, Bradley RS, Diaz HF, Baraer M, Caceres EB, Forsythe N, Greenwood HF, Hashmi G, Liu MZ, Miller XD, Ning JR, Palazzi LAOhmura, Rangwala EI, Schöner W, Severskiy I, Shahgedanova M, Wang MB, Williamson SN, Yang DQ (2015) Elevationdependent warming in mountain regions of the world. Nat Clim Change 5(5):424-430. https://doi.org/10.1038/nclimate2563

Pietikäinen JP, Markkanen T, Sieck K, Jacob D, Korhonen J, Räisänen P, Gao Y, Ahola J, Korhonen H, Laaksonen A, Kaurola J (2018) The regional climate model REMO (v2015) coupled with the 1-D freshwater lake model FLake (v1): Fenno-Scandinavian climate and lakes. Geosci Model Dev 11(4):1321-1342. https://doi. org/10.5194/gmd-11-1321-2018

Prein AF, Langhans W, Fosser G, Ferrone A, Ban N, Goergen K, Keller M, Tölle M, Gutjahr O, Feser F, Brisson E, Kollet S, Schmidli J, van Lipzig NPM, Leung R (2015) A review on regional convection-permitting climate modeling: demonstrations, prospects, and challenges. Rev Geophys 53(2):323-361. https://doi. org/10.1002/2014rg000475

Rangwala I, Sinsky E, Miller JR (2013) Amplified warming projections for high altitude regions of the northern hemisphere mid-latitudes from CMIP5 models. Environ Res Lett 8(2):024040. https://doi. org/10.1088/1748-9326/8/2/024040

Remedio AR, Teichmann C, Buntemeyer L, Sieck K, Weber T, Rechid D, Hoffmann P, Nam C, Kotova L, Jacob D (2019) Evaluation of new CORDEX simulations using an updated Köppen-Trewartha climate classification. Atmosphere 10(11):726. https://doi. org/10.3390/atmos10110726

Riahi K, Rao S, Krey V, Cho C, Chirkov V, Fischer G, Kindermann G, Nakicenovic N, Rafaj P (2011) RCP 8.5-a scenario of comparatively high greenhouse gas emissions. Clim Change 109(1-2):33. https://doi.org/10.1007/s10584-011-0149-y

Roeckner E, Arpe K, Bengtsson L, Christoph M, Claussen M, Dümenil L, Esch M, Giorgetta MA, Schlese U, Schulzweida U (1996) The atmospheric general circulation model ECHAM-4: Model description and simulation of present-day climate

Ruckstuhl C, Philipona R, Morland J, Ohmura A (2007) Observed relationship between surface specific humidity, integrated water vapor, and longwave downward radiation at different altitudes. J Geophys Res Atmos 112(D3):D03302. https://doi. org/10.1029/2006JD007850

Seneviratne SI, Donat MG, Pitman AJ, Knutti R, Wilby RL (2016) Allowable $\mathrm{CO} 2$ emissions based on regional and impactrelated climate targets. Nature 529(7587):477-483. https://doi. org/10.1038/nature16542
Shi Y, Wang G, Gao X (2018) Role of resolution in regional climate change projections over China. Clim Dyn 51(5-6):2375-2396. https://doi.org/10.1007/s00382-017-4018-X

Song L, Wang L, Chen W, Zhang Y (2016) Intraseasonal variation of the strength of the East Asian trough and its climatic impacts in boreal winter. J Clim 29(7):2557-2577. https://doi.org/10.1175/ jcli-d-14-00834.1

Su B, Huang J, Fischer T, Wang Y, Kundzewicz ZW, Zhai J, Sun H, Wang A, Zeng X, Wang G, Tao H, Gemmer M, Li X, Jiang T (2018) Drought losses in China might double between the $1.5^{\circ} \mathrm{C}$ and $2.0^{\circ} \mathrm{C}$ warming. Proc Natl Acad Sci USA 115(42):1060010605. https://doi.org/10.1073/pnas.1802129115

Sun Y, Zhang X, Zwiers FW, Song L, Wan H, Hu T, Yin H, Ren G (2014) Rapid increase in the risk of extreme summer heat in Eastern China. Nat Clim Change 4(12):1082-1085. https://doi. org/10.1038/nclimate2410

Tang Q, Oki T, Kanae S, Hu H (2008) Hydrological cycles change in the Yellow River Basin during the last half of the twentieth century. J Clim 21(8):1790-1806. https://doi.org/10.1175/2007j cli1854.1

Tapiador FJ, Navarro A, Moreno R, Sánchez JL, García-Ortega E (2020) Regional climate models: 30 years of dynamical downscaling. Atmos Res 235:104785. https://doi.org/10.1016/j.atmos res.2019.104785

Taylor KE (2001) Summarizing multiple aspects of model performance in a single diagram. J Geophys Res Atmos 106(D7):7183-7192. https://doi.org/10.1029/2000JD900719

Tiedtke M (1989) A comprehensive mass flux scheme for cumulus parameterization in large-scale models. Mon Weather Rev 117(8):1779-1800. https://doi.org/10.1175/15200493(1989)117<1779:ACMFSF>2.0.CO;2

van Vuuren DP, Stehfest E, den Elzen MGJ, Kram T, van Vliet J, Deetman S, Isaac M, Klein Goldewijk K, Hof A, Mendoza Beltran A, Oostenrijk R, van Ruijven B (2011) RCP 2.6: exploring the possibility to keep global mean temperature increase below $2{ }^{\circ} \mathrm{C}$. Clim Change 109(1):95. https://doi.org/10.1007/s10584-011-0152-3

Wang L, Chen W, Zhou W, Huang R (2009) Interannual variations of East Asian trough axis at $500 \mathrm{hPa}$ and its association with the East Asian winter monsoon pathway. J Clim 22(3):600-614. https:// doi.org/10.1175/2008jcli2295.1

Wang X, Pang G, Yang M, Wan G (2016) Effects of modified soil water-heat physics on RegCM4 simulations of climate over the Tibetan Plateau. J Geophys Res Atmos 121(12):6692-6712. https ://doi.org/10.1002/2015JD024407

Wang F, Ge Q, Chen D, Luterbacher J, Tokarska KB, Hao Z (2018a) Global and regional climate responses to national-committed emission reductions under the Paris agreement. Geogr Ann A 100(3):240-253. https://doi.org/10.1080/04353676.2018.1488538

Wang X, Pang G, Yang M (2018b) Precipitation over the Tibetan Plateau during recent decades: a review based on observations and simulations. Int J Climatol 38(3):1116-1131. https://doi. org/10.1002/joc. 5246

Wang Y, Zhao W, Wang S, Feng X, Liu Y (2019) Yellow River water rebalanced by human regulation. Sci Rep 9(1):9707. https://doi. org/10.1038/s41598-019-46063-5

Wang X, Chen D, Pang G, Ou T, Yang M, Wang M (2020) A climatology of surface-air temperature difference over the Tibetan Plateau: results from multi-source reanalyses. Int J Climatol 40(14):6080-6094. https://doi.org/10.1002/joc.6568

Woldemeskel FM, Sharma A, Sivakumar B, Mehrotra R (2016) Quantification of precipitation and temperature uncertainties simulated by CMIP3 and CMIP5 models. J Geophys Res Atmos 121(1):317. https://doi.org/10.1002/2015jd023719

Wu J, Gao X (2013) A gridded daily observation dataset over China and comparison with the other dataset. Chin J Geophys 56(04):11021111. https://doi.org/10.6038/cjg20130406 
$\mathrm{Xu} \mathrm{C}, \mathrm{Xu}$ Y (2012) The projection of temperature and precipitation over China under RCP scenarios using a CMIP5 multi-model ensemble. Atmos Ocean Sci Lett 5(6):527-533. https://doi. org/10.1080/16742834.2012.11447042

Xu M, Xu H, Ma J (2016) Responses of the East Asian winter monsoon to global warming in CMIP5 models. Int J Climatol 36(5):21392155. https://doi.org/10.1002/joc. 4480

Xu J, Koldunov N, Remedio ARC, Sein DV, Zhi X, Jiang X, Xu M, Zhu X, Fraedrich K, Jacob D (2018) On the role of horizontal resolution over the Tibetan Plateau in the REMO regional climate model. Clim Dyn 51(11-12):4525-4542. https://doi.org/10.1007/ s00382-018-4085-7

Yang M, Wang X, Pang G, Wan G, Liu Z (2019) The Tibetan Plateau cryosphere: Observations and model simulations for current status and recent changes. Earth-Sci Rev 190:353-369. https://doi. org/10.1016/j.earscirev.2018.12.018

Zhang Q, Xu C-Y, Yang T (2009) Variability of water resource in the Yellow River basin of past 50 years, China. Water Resour Manage 23(6):1157-1170. https://doi.org/10.1007/s11269-008-9320-2

Zhang Q, Peng J, Singh VP, Li J, Chen YD (2014) Spatio-temporal variations of precipitation in arid and semiarid regions of China: The Yellow River basin as a case study. Global Planet Change 114:38-49. https://doi.org/10.1016/j.gloplacha.2014.01.005

Zhang Q, Zhang Z, Shi P, Singh VP, Gu X (2018) Evaluation of ecological instream flow considering hydrological alterations in the Yellow River basin, China. Global Planet Change 160:61-74. https://doi.org/10.1016/j.gloplacha.2017.11.012
Zhao Y, Xu X, Huang W, Wang Y, Xu Y, Chen H, Kang Z (2019) Trends in observed mean and extreme precipitation within the Yellow River Basin, China. Theor Appl Climatol 136(3-4):13871396. https://doi.org/10.1007/s00704-018-2568-4

Zhou T, Yu R (2006) Twentieth-Century Surface Air Temperature over China and the Globe Simulated by Coupled Climate Models. J Clim 19(22):5843-5858. https://doi.org/10.1175/jcli3952.1

Zhou B, Wen QH, Xu Y, Song L, Zhang X (2014) Projected changes in temperature and precipitation extremes in China by the CMIP5 multimodel ensembles. J Clim 27(17):6591-6611. https://doi. org/10.1175/jcli-d-13-00761.1

Zhu J, Huang G, Wang X, Cheng G, Wu Y (2018) High-resolution projections of mean and extreme precipitations over China through PRECIS under RCPs. Clim Dyn 50(11):4037-4060. https://doi. org/10.1007/s00382-017-3860-1

Zong Y, Chen X (2000) The 1998 Flood on the Yangtze, China. Nat Hazards 22(2):165-184. https://doi.org/10.1023/A:1008119805 106

Publisher's Note Springer Nature remains neutral with regard to jurisdictional claims in published maps and institutional affiliations. 